RADIAL ZONING OF LARGE LMFBRs, PART II:

\title{
AN ANALYTICAL APPROACH
}

\author{
by \\ Marcia J. King \\ Applied Physics Division
}

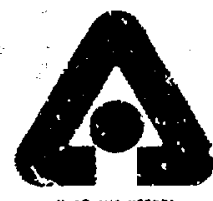

MASTER

ARGONNE MATIONAL LABORATORY, ARGONNE, ILLIMOIS

Prepared for the U. S. ENERGY RESEARCH

AND DEVELOPMENT ADMINISTRATION

under Contract W=31-109-Eng-38 
The facilitien of Argonne Narional Laboratory are awned by the United Stales Covernment. Under the terms of a contract (W-31-109-Eng-38) betwes the U. S. Enerey Research and Development Administration, Argonne Universtiet Astociation and The Iniversity of Chucreg. the Univeraity employs the taff and operates the Luboratory in accordance with policiea amt frogram formelated, approved and reviewed by she Association

\section{MEMBERS OF ARGONNE UNIYERSITIES ASSOCIATION}

The Univeraity of Arizoma Carnegie-Mellon Cnavezaity Cate Weatern Rasarve University The University of Chicago

Universily of Cinsinnati

Illinois Instituce of Technolngy

University of lltinois

Indiana Universiry

Join State lini.rer dity

The University if lown
Fianene State University The University of kinex. Loyola Univeraity Morquette Univeraity Michigan State Utiviveralty The Univeraity of Michigan Unveruty of Minnewota Univertily of Mineouri Northwestern Univeraty Universtey of Natre Dame
The Ohio Stale Untrersity

Ohio Unireraty The Penneyluenia State Univereity Purdue Univeraity Sinine Louis Untveratty Southern Illinot. Univeratiy The University of Texal at Austin Washingtun Universily Wayne State Univer aity The University of wiecontin

\section{NOFICE}

This Ieport was prepared as an wccount of work sponsored by the United States Government Neither the Unated Statez nur the United Slated Enotgy Researchind Development Administzation, nor any of thetr employees. nor any of their coitracturs. subcontractors, or their employect. makes any warganiy, expresu or implied. or anunut any leatl lability $0 z$ resposuikstity for the accuracy. completences or usefuiness of any information, apparstus proathce or proces: disiloned, or reprenent, that ity uer woutd not infringe privately-oxteat rights. Merition of conmersiat pecdurts. their manuficturers. Or their uppliess in tho publication dors not imply or connote approval or disapprowat of the product by Argonne Kiational Liboratnry or tic U. 5 Energy Research and Developrnerit Adrrinatration 


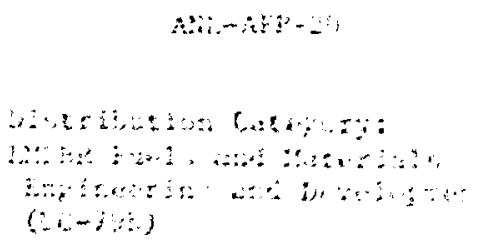

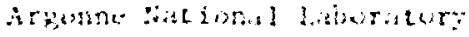

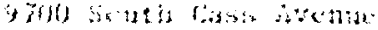

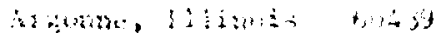

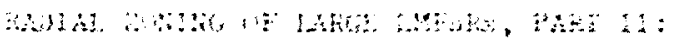

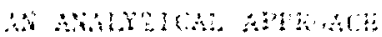

\author{
$13:$ \\ Xutriaj J. Kins \\ $\therefore \because \because \quad \therefore \because \therefore \because \therefore \because \because \because$
}

subust 3975 


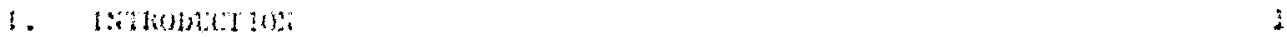

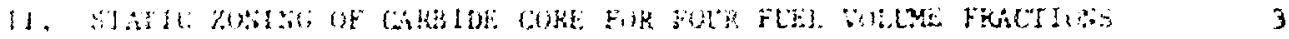

131. Hon

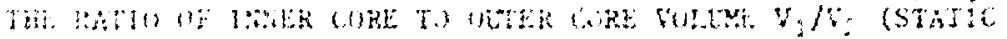

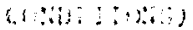

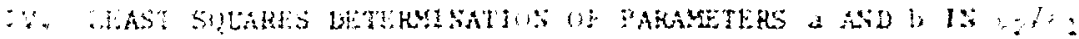

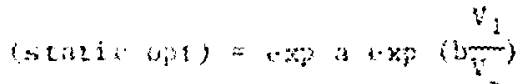

3

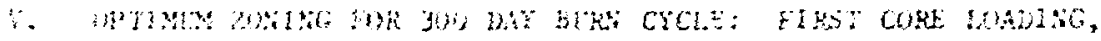

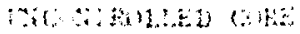

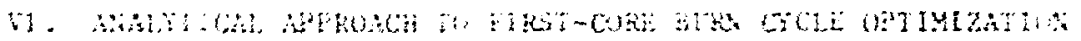

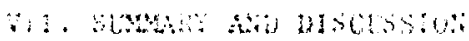

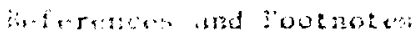


- paspepsuar ade:

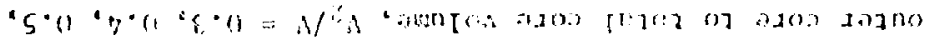

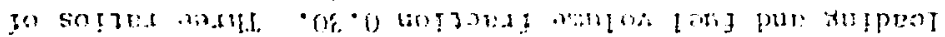

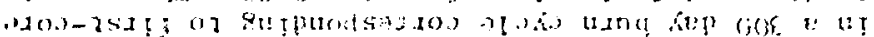

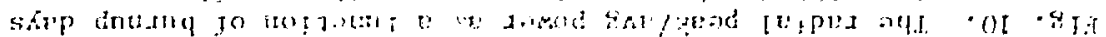

$\overline{6}$ $\because ;$

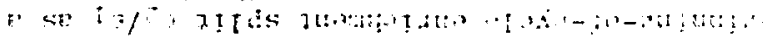

' sit: [\% ] [ [ [

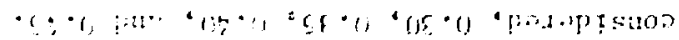

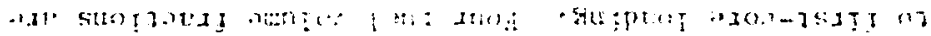

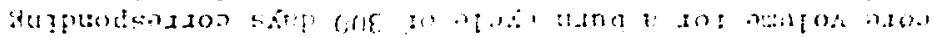

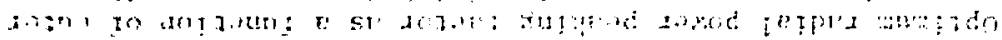

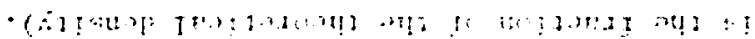

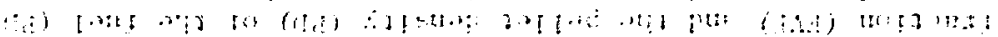

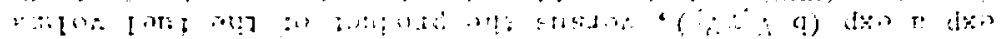

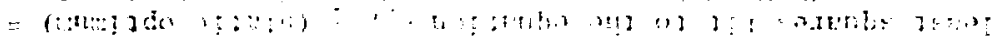

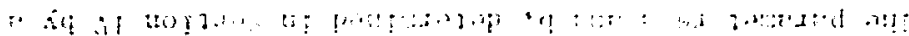

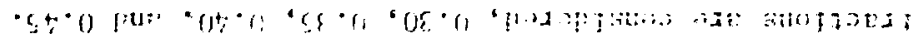
.

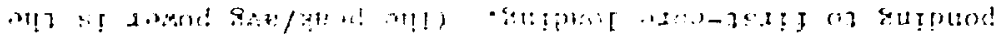

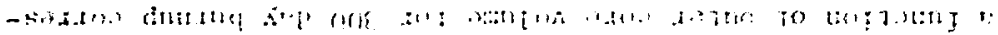


Fin. 11. The radial peiklayg power as a function of burnup jays in a 300 day burn $y$ cle corresponding to first-core loading and Evel volume jraction 0.35 . Three ratios of ouler core to lotal core volume, $\because \mathrm{V} / \mathrm{V}=0.3,0.4,6.5$, are considered.

Hig. 12. The radial jein/aves power as a iunction of burnup days

in a 300 day burn cycle cerrespondiag to first-core loaving and iuel volume fraction 0.40 . Three ratios of mater core to lotal core wolume, $v_{2} / v=0.3,0.4,0.5$, are considereil.

Hi. 13. Tiae radial iratiolag puwer as a function of burnup days in a 30 (tijy burn cycle corresponding to first-core löadia ind toel volume fraction 0.45 . Tinrex ratios of unter cor: to total core volume, $\ddot{v}_{2} / \vec{V}=0.3,0.4,6.5$, $a-\operatorname{considi} \cdot r \cdot d$.

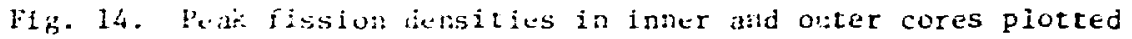
as is funtion of jurnup days 20 a $3 i 0$ day burn cycle corresponing io irstacore loadas ano fuel voluse

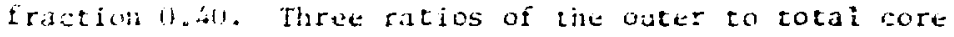
Yolute, $\because \because=11.3,0.4$, and 0.5 mate considered. The interseclion a: ricil pair of curves iortesponds to the

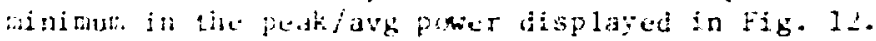

Fig. 15. Meak/ave gower (radial $x$ axial ${ }^{6}$ ) as a tunction of burmup days in a 300 ciy burn cycle (first-core loading) for cuel volune fraction $=0.45$, and outer core to total are volume $\because y=0.30$. The hegit.uing-of-cycle errichnent split,$f(B)(t)=1.353$ corresponcs to optimization of the power piaking factor, wile $: l(B O C)=1.3665$, i.3935, and $1.42 \%$ reprosent $1 \%, 3 \%$ and $5 \%$ banges in this input. resion tively.

Fig. 16. ítaklavg poiet (ra.

axtal) ve. fuel rolume fraction for a 300 day clo and ouler cote to total core volume $Y / Y=\cdot$ The lower curve shows the change in thit: facts. the beginning-of-cycle enrtchthent split is varied $\iota$, do from the ogtimur.

Fig. i7. The peak fisidon density of the inner coro is ploted as a Eunction st burnup days in a 300 bay burn eycle (iirstcore loddint). The beginuing-ot-eycle etridment split $f, /:=(B O C)=1.168$ corresponds to the optimum power peitiong fitcor for the givel: valume split, $V_{2} / N=0.5$, and fuel volurie traction $=0.45$. 


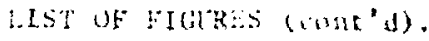

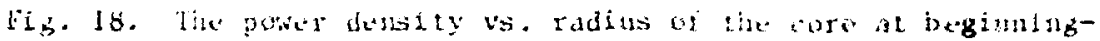

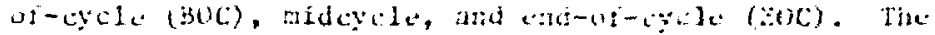

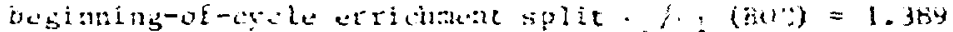

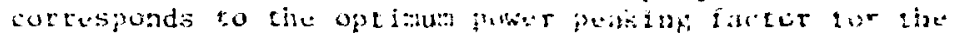

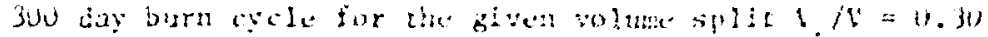

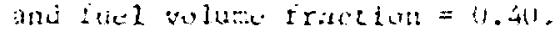

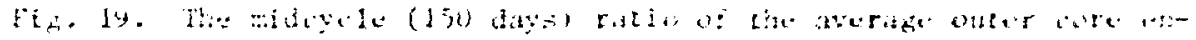

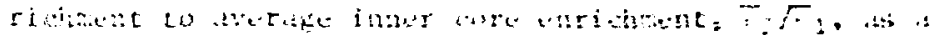

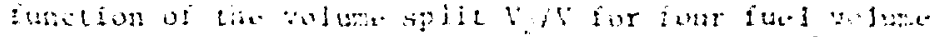

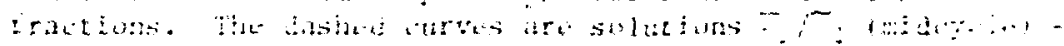
a +

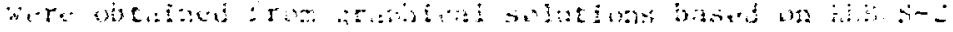

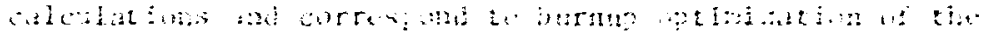

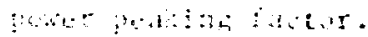

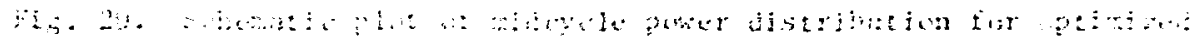

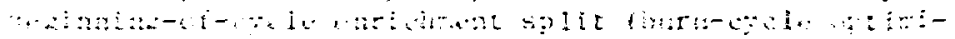

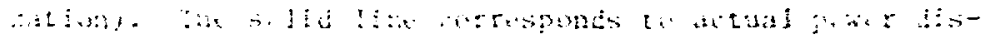

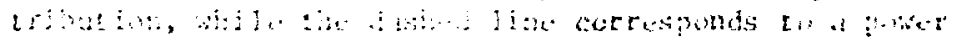

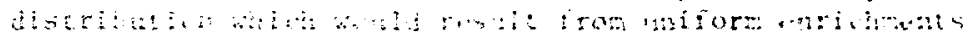

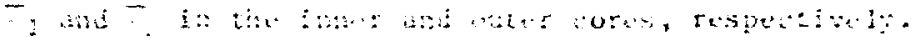

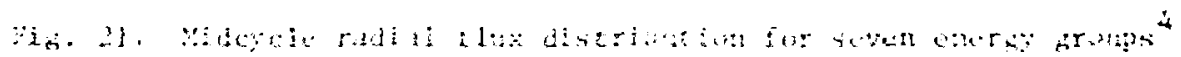

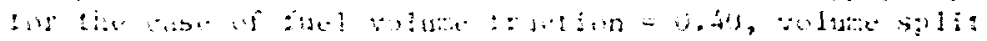

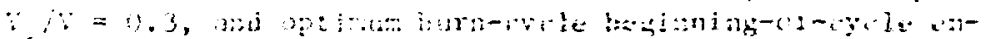

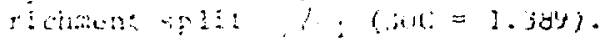

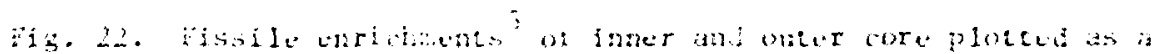

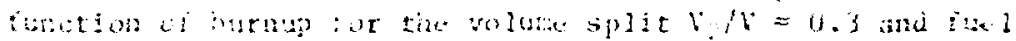

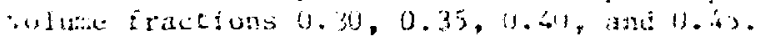




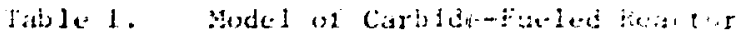

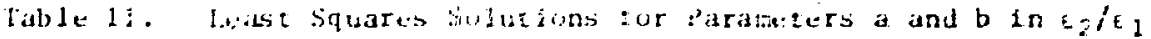

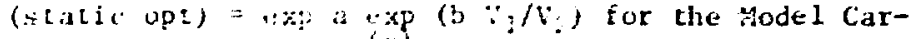
bite lore of lable I (ii)

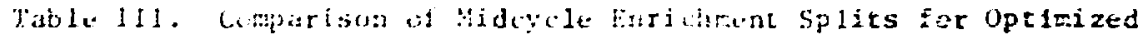

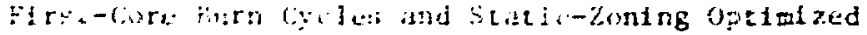

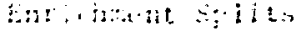




\begin{abstract}
ABSTKAC!
The optimus hucleat: radjal puwer peaking factor as a Function of radial zoning is invesed nated for larde carlice

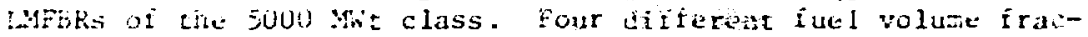
tions are considered. Tile two radial zenes are tharacterijed

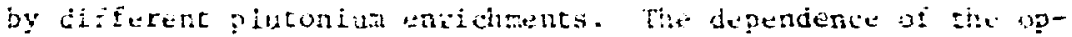
timun power peaising factor on the volume and erricinent ratios of outer to iner cure is investigated for static conditions ant for burn oles corresponiag io irst fore loading. $\therefore$ simple pinenotwological mudel is lised to determine the anccional dependence of the optinum enricrant split on the tatio of inner to outer core volume.
\end{abstract}




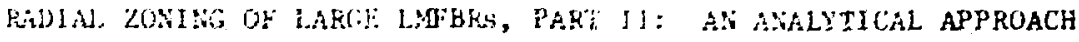

$$
\text { Sarcic J, ting }
$$

1. MrRoDucrion

Mininization of the nuclear power iveaking factor by neans of radial zoning is consldered for large lafpls of the 5000 shit class. For linest reactors, the opt inum racial power peaking factor exhibits a hroad minimini as a inction of the ratio of outer core to total core volume, but is entreme $1 \%$ sensftive to the ratio of outer to inrer core enrichnents. In this analysis, tie dependence of the optimum enrichment split on the volure ratio of the outer to inner core is investlgated for statfc conditions and for the burn cycle corresponding to ifrst-core loading. A finite-cylinder uncontrolled core, chree leet in height ind approximately 200 cri radius was chosen to simulate the actual reactor core. The two radial zones of the core are characterized by different plutonium enrichments. Carbide fuel was used is the study.

The plan of the report is as follows: In Section il, the results of the static zonfng analysis based on MARCAD neutronic calculations are distussed. A peliet density of $95 \%$ T.D. was assumed for the carbice Fuel and fuel volume fractions $0.30,0.35,0.40$, and 0.45 were considered. A family of curves for the optimum enrichment split $5 /{ }_{2}$ vs. the ratio of the outer to total core volume $V_{/} / V$ are anong the graphs included.

In Section III, we explore a simple analytical approach based on an idealized model to determine the optimum: $/ E_{1}$ as a function of $v_{1} / v_{2}$. From this analysis we extract a phenomenological relation containing two parameters thich depend on the matertal pxoperties of the core. 
In Section IV, these parameters are determined by a least squares fit for the nodel core and a comparison of the results with the data obtained in Section II is made.

Section $y$ includes a discussion of the optimization reaults for $G$ first core burnups. Calculations were based on the 1-D version of the REBUS-2 code. It Section vI, 1s shown that the analytical approach of Section III is appropriate for the determination of the midiycle ratio $\varepsilon_{2} / \varepsilon_{1}$, where $\varepsilon_{1}$ and $\bar{\varepsilon}_{z}$ are the average inner and outer core enrichments. The extrapolation te the beginning-of-cycle optimun enrichment spitt is discussed.

Section VIJ contains a sumary and discussich of the

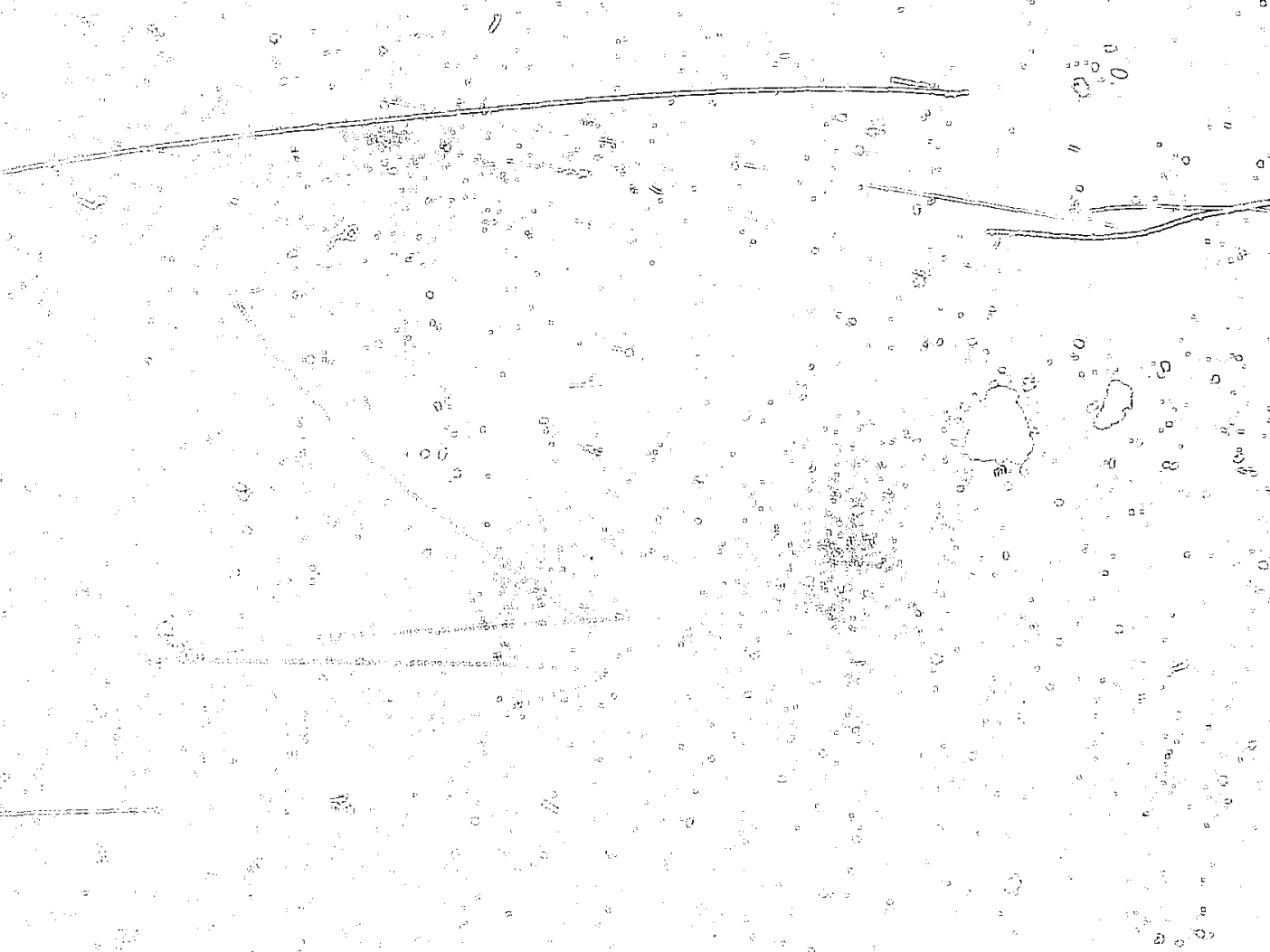


11. STATIL EUNLING OF CARBIDE CORE FOR FOUR FULL VOLURE FRACTIONS

The assuintions for the model carbide reactor are summarized in

Table 1. The lack of an axial blanket is a reflection of the one-dimersional calculations. The core is assumed to be uncontroiled and unpoisoned and its fuel composition corresponds to beginring-of-cycle conditions. Ten percent of tile power is taken to come from radial and axial blankets, so that the core is characterized bÿ a power of $4500 \mathrm{MWt}$. Four cases are considered, correspondisg to fugl volune fraction (FVF) $=0.45,0.40,0.35$, and 0.30 respectively. The atom density usef in the neutronic calculatior (based on $\mathrm{DARC1D}^{2}$ ) corresponds to a pellet density of $95 \%$ T.D. The plutonium enrichnent is defined as $\varepsilon=$ mass of fissile plutonium isotopes/mass of the heavy metal.

For a fixed ratio of the outer core volume to total core volume, $V_{2} / V$, the ratio of outer to inner core enrichment, $\varepsilon_{2} / \varepsilon_{1}$, was varied \pm 0 determine tíse minimum radial power peaking factor. The resulting curves, examples of which axe given in Fig. 1 (see also Reference 1) take the furmo of. "vees"; the first leg of cach "vee" corresponds to the peak powet sccuiring at the center of the core, while the second leg corresponds to peaking in the outer core. Fig. 2 displays the broad mij nima near $v_{2} / V=0.3$ in the radial peak/average power ratio as a function of $V_{2} / V$ for the four fuel volume fractions considered. In the range $v_{2} / V \simeq 0.2$ to 0.4 the optimum powe: peaking factor varies by less than $2 \%$. It is a decreasing function of the fuel vc lume fraction.

Plots of the optimum $\varepsilon_{2} / E_{1}$ versus $V_{2} / V$ for the four cases appear in Fig. 3. The dashed lines, which closely cverlap the curves excrpt in the resion $V_{2} / V \lesssim 0.25$, correspond to the predicted optinum $\varepsilon_{2} / \varepsilon_{1}$ from the analysis described in Sections II and IV. 
III. FUNCTIONAI DEPENDENCE DF OPTIMIZED ENRICHMENT ' PLIT $\varepsilon_{2} / \sigma_{1}$ ON THE RATIO OF INNER CORE TO OJIER CORE VOLUME $v_{1} / v_{2}$ (STATIC CONDITIONS)

As shown in Section II of this report, for a given choice of $v_{2} / v$, tiie radial power peaking factor is a sensitive function of the enridhment split $\cdot{ }_{2} / E_{1}$. Since the opttrized power peaking factor has a broad minimum as a function of $V_{2} / V$, the practical probiem is reduced to the determination of the optimum enrichment split as a iunction of $v_{2} / v$.

In :hfs section we adopt an 1dealized model in order to understand the general features of such a relation between $\varepsilon_{2} / E_{1}$ and $V_{1} / V_{2}$. This model, illustrated in Fig. 4, is tased on a number of assumptions which aro described below. The validity of these assumptions for the neutronic calculations cescribed in Section II is discussed.

We shall assume that for a given choice of the radius of the inner core $R_{1}$, the plutonium enrichments $\varepsilon_{2}$ and $\varepsilon_{1}$ are such that the power densities at the center of the core $(r=0)$ and at the inner boundary of the outer zone $\left(r=R_{1}\right)$ are equai. This corresponds to the (static) minimum radial power peaking factor foi tine given volümes $V_{l}$ and $V_{2}\left(R_{2}\right.$ and $R$ are heid fixed throughout). Further, for $v_{2} / V$ in the optimum range, $v_{2} / v \bumpeq 0.2$ to 0.5 , we assume

a) the radial flux in the inner core is an extremely slowly decreasing function of the radius $r$,

b) the radial flux in the outer core is also slowly decreasing with increasing $r$, but its curvature is much greater than the corresponding curvature of the inner rore flux,

c) the flux is zero at the radial boundary of the reactor, $r=R$, 
d) in all three regions, the flax is separable as a function of energ; and space, 1.e.,

$$
\downarrow(E, r, z)=C(E) \phi(r) \%(z)
$$

The neutronics calculatiens described in Section II were based on the ARC System One-3mensional Diffuston Theory Capability, DARC1D, ${ }^{2}$ and exght energy groups were used in the multigroup analysis. ${ }^{4}$ In Fig. 5, we have plcted the first seven flux groups tu= a particular case of the carbide model reactor corresponding to $\mathrm{FV} \vec{r}=0.4, \mathrm{~V}_{2} \cdot \mathrm{V}=0.4$, and an optimurenrichment split $\varepsilon_{2} / \varepsilon_{1}=1.2055$. The assumptions chove can be considered as falriy accurate for the inner core, less so for the outer core and the ragions of tive blanket and reflector. Therefore, we look for the idealized model to give the overall behavior of $\varepsilon_{2} / \varepsilon_{1}$, with corrections to be introduced later.

The assumption (d) implies trat the radial solutions in the tinree reglons cin be expressed by

$$
\begin{array}{ll}
A_{1}(r)=A_{0}\left(\beta_{1} r\right), \quad 0 \leq r \leq R_{1} ; & \\
\phi_{2}(r)=\operatorname{CJ}_{0}\left(\beta_{2} r\right)+D Y_{0}\left(\beta_{2} r\right), & R_{1} \leq r \leq R_{2} ; \\
\phi_{3}(r)=E_{0}\left(\beta_{3} r\right)+F Y_{0}\left(\beta_{3} r\right), & R_{2} \leq r \leq R ;
\end{array}
$$

while the axial solution in all three regions is

$$
Z(z)=A^{\prime} \cos (\alpha z), \quad 0 \leq|z| \leq H / 2 .
$$

where $\alpha$ satisfles $\tan \left(\alpha \frac{H}{2}\right)=\frac{1}{d}$, and $H$ is height of reactor, $d=$ the extrapolation distance. The radial buckling $\beta_{i}$ and axial buckling $\alpha$ satisfy

$$
B_{1}^{2}=\alpha^{2}+\beta_{i}^{2}, \quad 1=1,2,3 .
$$


where $B ?$ is the buckling in region $i$ of the reactor. In lerns of the average ditfusion coeficient $b$ and averige talcroscopic cross rections, the one-enerpy buckling is

where

$$
B_{i}^{2}=\frac{\left(\bar{j}_{i}\right)_{i}-\left(\bar{i}^{2} i\right.}{n_{i}}
$$

$$
\begin{aligned}
& \bar{Z}_{\mathrm{f}}=\text { average macroseopio tisision cross sertion } \\
& \bar{Y}_{a}=\text { average macroscopi.: absorption cross section of fuel and } \\
& \text { roditatgis (coolant, structure). }
\end{aligned}
$$

Fron Eqs. (3.5) and (3.6) we know that the radial buckling is a linear function of enrichnent. We shall wite

$$
\dot{i}=E_{i} \ddot{E}_{i}-g, \quad i=1,2
$$

and to the first approximition, the paraneters $f$ and $g$ are taken as indeptndent of inner and outer core properties. Thus we have

$$
\frac{\varepsilon_{2}}{\varepsilon_{i}}=\frac{B_{2}^{2}+g}{\sigma_{1}+g}
$$

Applying the boundary conditions on the fluxes and the nornal currents at $r=R_{1}, R_{2}$, and $R$, and assuming the diffusion coefficients of the inner and outer core are approximately equal, we obtain the following condition for solution:

$$
\begin{aligned}
& J_{0}\left(\beta_{1} R_{1}\right) \quad-J_{0}\left(B_{2} R_{1}\right) \quad-Y_{0}\left(\beta_{2} R_{1}\right) \quad 00 \\
& J_{0}^{\prime}\left(\beta_{1} R_{1}\right) \quad-J_{0}^{\prime}\left(\beta_{2} R_{1}\right) \quad-Y_{0}^{\prime}\left(\beta_{2} R_{1}\right) \quad 00 \\
& 0 \quad I_{0}\left(B_{2} R_{2}\right) \quad Y_{0}\left(B_{2} R_{2}\right) \quad-J_{0}\left(B_{3} R_{2}\right) \quad-Y_{0}\left(B_{3} R_{2}\right) \quad=0 \text { (3.9) } \\
& 0 \quad J_{0}^{\prime}\left(B_{2} R_{2}\right) \quad Y_{0}^{\prime}\left(B_{2} R_{2}\right)-\frac{\bar{D}_{3}}{\bar{D}_{2}} J_{0}^{\prime}\left(B_{3} R_{2}\right)-\frac{\bar{D}_{3}}{\bar{D}_{2}} Y_{0}^{\prime}\left(B_{3} R_{2}\right) \\
& 0 \\
& 0 \\
& J_{0}\left(B_{3} R\right) \quad \dddot{i}_{0}\left(B_{3} R !\right.
\end{aligned}
$$




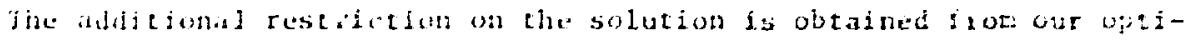
nis at jua custition, namely

$$
i^{\prime}(r=0)=B^{\prime}\left(r=H_{1}\right)
$$

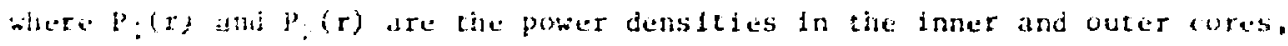

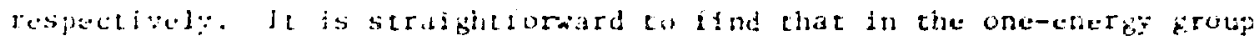

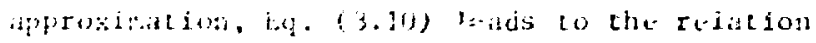

$$
\frac{1}{21}(0, t \text { inumi })=3(\therefore, H)
$$

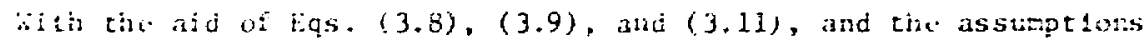
(a) Larough (a), we nay express ab ratial bachling to as an toplicit

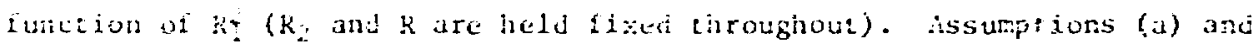
(i) Wi.g be translated to reiad

$$
\begin{aligned}
& \Leftrightarrow \quad \because R \div \cdots ! \\
& \text { (i) } \because k 901 \\
& 10 \times 2
\end{aligned}
$$

dnd for small arguments tile Bessel functions and their derivalives can be approximated by

$$
\begin{aligned}
& J_{0}(x)=1-\left(\frac{2 x}{2}\right) \\
& J_{0}^{\prime}(b r) \simeq-\frac{e^{\prime} r}{2} \\
& y_{0}(i r) \simeq \frac{2}{11}[1 n \div-0.11593] \\
& Y_{0}^{\prime}(B r) \geq \frac{2}{I l r}
\end{aligned}
$$




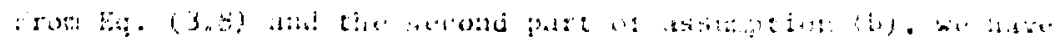

$$
\because \therefore \frac{3 ! 3}{4}
$$

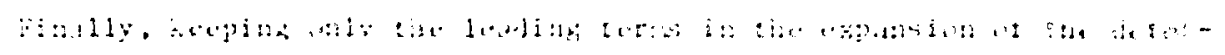

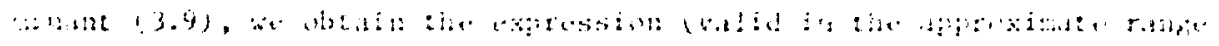

$$
\begin{aligned}
& \because-4.2:(1.3) \\
& \because-\frac{a}{i}\left[\frac{1}{n !}+\frac{1}{i ! n !}\right]
\end{aligned}
$$

$\therefore: \cdots$

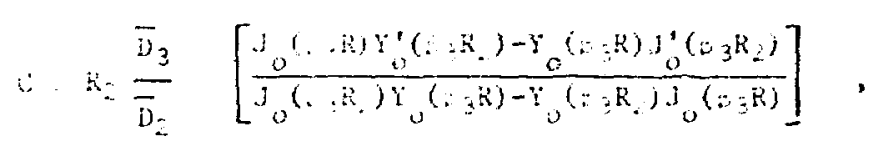

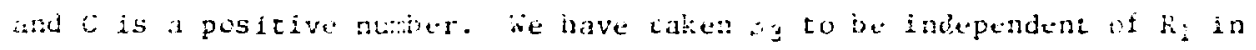

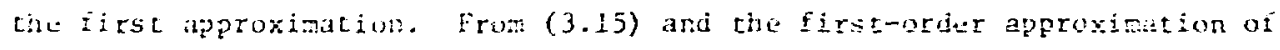
$j_{0}\left(a: R_{i}\right)$, it follows tiant

$$
\frac{E}{E}=1+\frac{C}{b}+\frac{C}{g} \frac{4 i}{k-R i}=1+\frac{C}{g}+\frac{C}{g} \frac{V_{i}}{v_{2}}
$$

Eqs. (3.7) and (3.15) imply the following: as we vary ly noldine $v=v_{1}+v_{2}$ fixed, the walue of $s_{1}$ corresponding to optimum $\varepsilon_{z} / t_{2}$, (i.e., the optimized power peaking, is a symerrical function of $v_{1}$ and $v_{2}, i . e$.

$$
E_{1} \propto \frac{1}{V_{1} V_{2}}+\operatorname{constant} \text {. }
$$

Then $E_{1}$ has a minimum at $V_{3} / V=V_{2} / V=\frac{1}{2}$. A compariscal of this frediction witi tise data obtained from the neutronics calculations described in Section 11 indicates thit this is a good approximation. This is demonstrated in Fig. 6 , whice the optimum inter core enrichment $E_{1}$ has been plotted as a function of $v_{2} / V$ for the four fuel volume fractions $0.45,0.40,0.35$, and 0.30 . 


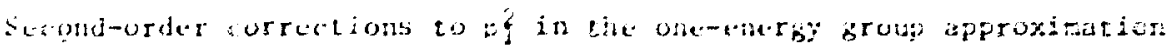
rould be included by keeplag bigher-order cerms in the expansions of tine

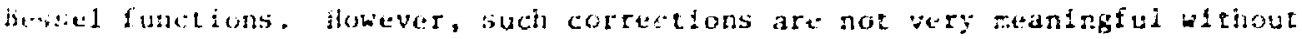

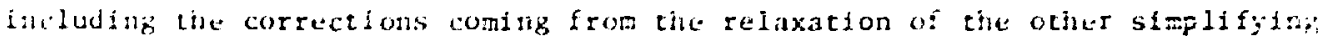
assumptionts. Insteit o: enbarking on at nore detaled analysis, we note that lise gotarial featuress of our results are retained if we assume

$$
\frac{2}{\therefore 2} \text { (stitif opt) }=\exp \text { is axp }\left(\mathrm{b} \frac{v_{\vdots}}{v_{z}}\right) \text {, }
$$

wilin $1 \leftrightarrow 1, b \therefore 1$. Tha parameters remain to be determined. We regard Ey. (3.ju) as a pintomenological relation, and snvestigate its application to tine model carbide core in the rext secton.

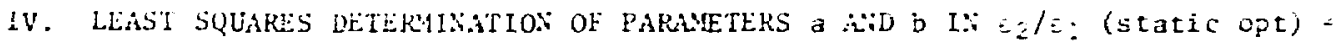
exp a exp $\left(b \frac{v_{1}}{v_{i}}\right)$.

The form of Eq. (3.19) lents itself readily to a simple least squares decermination of the parameters a and b. Since the relation is expected to be accurate only in the optimum range of $V_{2} / V$, and because the exponentiai function is smoothly varying, the fit was simplified by limiting it :o three data points at $V_{2} / V=0.3,0.4,0.5$. The corresponding values of optimum $\varepsilon_{2} / t_{1}$ were obtained from the neutronic calculations based on DARCID and describti : a Section 11 .

Letting

$$
\begin{aligned}
& y_{1} \equiv \ln \left(\varepsilon_{2} / \varepsilon_{1}\right)_{i}, \quad i=1,2,3 \\
& x_{1} \equiv\left(v_{1} / v_{2}\right)_{1},
\end{aligned}
$$


$4: 3$

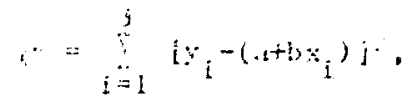

in. (ni) tain sulutians to the equations

$$
\frac{2 \cdot}{2.1}=0, \frac{21}{2 b}=0
$$

ias? ate siven by

$$
a=\left[\sum_{i=1}^{j} y_{i} \sum_{i=1}^{3} x_{i}-\sum_{i=1}^{3} x_{i} \sum_{i=1}^{3} x_{i} y_{i}\right] /\left[\sum_{i=1}^{3} x_{i}-\left(\begin{array}{cc}
3 & \\
\vdots & x_{i}
\end{array}\right)\right],
$$

and

$$
\dot{b}=\left[3 \sum_{i=1}^{3} x_{i} \ddot{i}_{i}-\sum_{i=1}^{3} x_{i} \sum_{i=1}^{3} y_{i}\right]\left[3 \sum_{i=1}^{3} x_{i}^{2}-\left(\sum_{i=1}^{3} x_{i}\right)\right]
$$

Tuble 11 contains the solutions for a and b for the model carbide réactor described in Section il (see Table I) and for the four fuel volume fractions considered. In Fig. 3, the solutions to Eq. (3.19) based ori these values of $a$ and $b$ have been pioted (dashed lines) along witi the solutions obtained by means of the DARCID neutronic calcu?ations described in Section II (solid Lines). The agrement is extremely good in the raso $V_{2} / V=0.25$ to 0.6 . The parameters $a$ and $b$ have been plotted in Fig. 7 aw functions of the product of the pellet density and the fuel volume fraction, pD*FuF. The variable TD*FVF was chosen because the neutronics calrulations are based on this product. Therefore, $a$ and $b$ may be determined for other pellet densities by means of this grapil or by interpolation $1 \mathrm{n}$ Tabie II. 
v. UP'TMUM ZONIRG FOR 300 DAY BURN CICLE: FIRST CORE LOADING, URCONTROLLED CORE

In general, tine power distribution in the laige LMPBR core changes shape as burnup proceds. Addition or suberaction of contral poison can be done in such a way as to minimze this change and shus to minimize the change in the nuclear power peakir.p factor. The statc, or beginning-of-cycle, zoning optimizat ion woudd be appropriate in this case. For the uncontrolled core, optinization of the puwer peaking factor must be defined differently.

For the range of fuei yolume fractions under consideracion, the conversion ratio of the inner core is always greater than unit. I is aiso greater than the outer core conversion ratio. As a result, since the total power remains constant, the power densizy at the core center Increases with burnup, while it decreases in the outer core due to power buildup in the inner core and in the radial blanket. Thus, for example, the peak power may occur in the outer core at the beginning of cycle but may shift to the core center by the end of cycie. For the uncontrolled cote, the optimum zoning corsesponds to tinis situation, wt th the additional condition that the magnitude of the peak/average power ratio of the core be the same at beginning, and end of cycle.

A 300 day burn cycle corresponding to firsi-core loading was considered for the model carbide reactor of Table $I$. kefe was taken to be unity at the beginning of cycle for the fuel volume irachions $0.45, j .40$, and 0.35 , where the reactor gains reactivity during burnup, and at the end of cycle for $F V F=0.30$, where the reactor loses reactivity. For fixed outer to total core volume ratio, $V_{2} / V$, the beginning-of-cycle enrfchment split, $\varepsilon_{2} / \varepsilon_{1}$ (BOC), was determlned from REBUs-2 ${ }^{(3)}$ calculations to meet the conditions for optimling the radial power peaking factor. The resulting optimum power peaking factors are plotted as functions of $v_{2} / V$ in Fig. 8. As expected, these factors 
are higher lihan in tho statis zoning. Howsever, tize dependence on the fur: 1 volume fraction is reversed: the power peaking faclor increases with intreising Wf in buroup optimiz. ison. Also, tile broad minima of the power peaking factors are shifted to larger values of $V_{2} / V$ compared to the static case. The corrksiponding optimized $\varepsilon_{2} / E_{1}(B O C)$ are plotted as a function of $v_{2} / v$ in fig. 9 . In Figs. 10-13, the dependtuce of the radial peak/average power on tinc number of days of buraup is shown. In each case, the burn cycle has been optimized, i.e. the optimum radial power peaking factor Is given by the Buc or EOC value of tire peak/average power. During the first part of the cycle, tile peak/average puwer decreases as the peak power, occurring in the outer core, decreases. At the time when the peak power occurs simultaneously at core center and in the outer core, the curve reaches a minimum. The increasing power density of the inner core is then responsible for tile rising curve to the end of the burn cycle. In Fig. 14, the peak fission density of the inner and outer core, respectively, is plotted as a function of burnup days for a representative cdse, FVF $=0.40$. The intersections of each pair of curves corresponds to the ninimat in the peak/average power in Fig. 12 (not to be confused with the optimur nucliar power peaking factor for the burn sycle).

The belavior of the power distribution during burnup showed great sensitivity to small changes in the input $\varepsilon_{2} / \varepsilon_{1}$ (BOC). This sensitivity is illustrated in Figs. 15-17. In Fig. 15, where the peak/average power vs - burnup days is plotted for $F V F=0.45$ and $V_{2} / V=0.30$, a $3 \%$ change in $\varepsilon_{2} / \varepsilon_{1}$; BOCi, for instance, results in a $9 \%$ change in the optimum power peaking factor. Moreover, the whole character oí the burn cycle is changed, with the peak/average power in the core steadily decreasing from beginning to end of cycle. In 18. 16, where the peak/average power is given as a function of the fuel volume fraction, this sensitivity is shown to increase with increasing fuel volume fraction: a $1 \%$ change $i, 1 \varepsilon_{2} / \varepsilon_{l}$ (BOC) causes $2 \%$ and $3 \%$ changes th the peaking factor for 
$F V y=0.30$ and $\mathrm{FF}=0.45$, respecrively. Finaliy, $\overrightarrow{F 1 g} .17$ is inciuded to demonstrate the seisitivity of the end-of-cycle fission density at core center io small variations in $\varepsilon_{2} / s_{1}(B O C)$. Here we see that in the case $F V F=0.45$, $V_{2} / V=0.5$, a $1 \%$ change in $\varepsilon_{2} i{ }_{1}$ ( $(B O C$ ) can result in an $8 \%$ variation in the end-of-cycle fission density at core center.

This extreme senstivity, characteristic of the large fuel voiume fractions of the large LMrBRs, makes it very importast to determine the optinu $L_{2} / \mathrm{l}$ (BOC) as accurately as possible. Alchough some performance characteristics sucil as tixe reactor breeding atio remain relatively insensitive to changes in tite cnrichment ratio, others such as fluence, burnup swing $\angle k / k$, will je rore strongly affected. Therefore, it is worthwhile to investigate the possibilit: of extending the static zoning analysis to include the first-core burn cycle. This analysis is described in the next section.

VI. ANALYTICAL APPROACH TO FIRST-COKE BLRN CYCLE OPTIMIZATION We recall that the condition for optimum static zoning was that the power derstey peak simultaneously in the inner and outer core. This provided the constraint $P_{1}(r=0)=P_{2}\left(r=R_{1}\right)$ given in Eq. (3.10), which, in addition to the boundary conditions on the flux enabled us to derive a relation for $E z / E_{\text {? }}$ (static optimum). We might at first expect, then, that we cculd apply a similar analysis to the core valid at a given time durfng the burn cycle when sinilar conditions exist, namely when the peak/average power is a minimum (see, e.g., Figs. 12 and 14). This is not a valid assumption, however, because the plutonium enrichment, uniform in each core, low at the beginning of cycle, becomes a function of radius during burnup. For example, at midcycle, the Inner core enrichment increases wth radius, In general, from core center to the outer zone in the optimized 
case. This is because the beginniag-of-cycle power distribution peaks in the inner core at its outer boundary; see, for example, fig. 1s. On the otiler hand, the midcycle enrichment of the outer core decreases with increasing radius.

Nevertheless, we shall be able to apply the analysis of Section III if we use tine volume-averaged enrichments of the inner core $\bar{E}_{1}$ and of the out r core $\bar{\varepsilon}_{2}$. Imagining a core fueled with uniform enrichments $\bar{\varepsilon}_{1}$ and $\bar{z}_{2}$ in the inner ani outer cores, respectively, we define the corresfonding fluxes $\phi_{1}\left(\overrightarrow{c_{i}}, \vec{r}, t\right)$ anc $\theta_{2}\left(\bar{\varepsilon}_{2}, \vec{r}, t\right)$ and power densities $P_{1}\left(\bar{\varepsilon}_{1}, \vec{r}, t\right)$ and $P_{2}\left(\bar{\varepsilon}_{2}, \vec{r}, t\right)$. For these quantities, we shall assume that at sore time $t^{\prime}$ during the burn cycle, ise conditions for static optimization are met, namely,

$$
P_{1}\left(\bar{\varepsilon}_{1}, r=0, t^{\prime}\right)=P_{2}\left(\bar{\varepsilon}_{2}, r=R, t^{\prime}\right)
$$

and that conritions (a) - (d) of Sect. II hold. Then, carrying out tihe sane analys;s as in Sect. III, we expect

$$
\frac{\bar{\varepsilon}_{2}}{\bar{\varepsilon}_{1}}\left(t=t^{\prime}\right)=\exp a^{\prime} \exp \left(b^{\prime} \frac{v_{1}}{v_{2}}\right)
$$

where $t^{\prime}$ is the time at which (6.1) holds, and $a^{\prime}$ and $b^{\prime}$ are parameters analogous zo those determined in Sect. III.

If Eq. (6.2) is to be useful, the time to reach "optinization conditions", namely $t^{\prime}$, should be independent of $V_{1} / V_{2}$ and also of FVF. The simplest assumption is that $t^{\prime}$ corresponds to midcycle, in our case, 150 days. We found, in fact, that $\bar{\varepsilon}_{2} / \bar{\varepsilon}_{1}$ (midcycle) corresponding to the optimized burn cycle is in remarkably close agreement with $\varepsilon_{2} / \varepsilon_{1}$ (static optimum), in strong support of 
the assumptions above. This is demorstrated in Table III. Comparisons of $\bar{t}_{2} / \bar{c}_{1}$ (midcycle) to values calculated from

$$
\bar{c}_{2} / \bar{E}_{1}\left(\text { midcycle) }=\exp a \exp b \frac{v_{1}}{v_{2}}\right.
$$

are given in Fig. 19, where a and b were taken from Table II.

Thus we conclude that $\underline{\exists}^{\prime} \underline{\simeq}$ and $b^{\prime} \simeq b$. We recall that for static zoning in the unpoisoned core, a and b were approximately linear functions of PD $x$ FVF, i.e. the product of the pellet density and the fuel volume fraction. The identification $a^{\prime} \simeq a$ and $b^{\prime} \simeq b$ can be made if we consider $a$ and $b$ to be functions of the product of the "fuel" pellet density and "fuel" volume fraction, where "fue 1 " denotes the fuel plus the accumulated fission products (in the simulated reactor burnup of REBUS-2, (3) these quantities remain almost constant during burnup).

It is important to note that the actual power distribution at widcycle wili not correspond to $P_{1}(r=0)=P_{2}\left(r=R_{1}\right)$. This is illustrated schenaticaily in Fig. 20, and also in Fig. 18. However, the effect of the sinall radial variation in $\varepsilon_{1}$ and $\varepsilon_{2}$ at midcycle should have only a second-order effect on the flux shape, since, e.g., $J_{0}\left(\beta_{1} r\right) \simeq 1-\frac{\beta_{1}^{2}}{4} r^{2}$, and the buckling $z_{1}^{2}=\varepsilon_{1}+$ const. This is born out by comparison of F1gs. 5 and 21 . In the former, the flux groups are plotted for a case of static optimization. The latter shows the midcycle flux groups for an optimized burn cycle.

In order to estimate $\varepsilon_{2} / \varepsilon_{1}(B O C)$ for the optimized burn cycle, we consider the time rate of change of the enrichments $\varepsilon_{l}$ and $\varepsilon_{2}$. Since these quantities change slowly and approxtmately linearly with burnup (see, e.g., Fig. $22^{5}$ ), to a very good approximation, we can write

$$
\bar{\varepsilon}_{i}(t)=\varepsilon_{i}(B O C)\left[1+\alpha_{i} t\right], i=1,2
$$


where $a_{i}$ is a constant which can be determineu from any burnup calculation bitin a burnstep of length, say, $t_{1}$ :

$$
\alpha_{i}=\left[\frac{\bar{\varepsilon}_{i}\left(t_{1}\right)}{\varepsilon_{i}(B \circlearrowleft C)}-1\right] / t_{1}, i=1,2
$$

It follows then that the optimized beginning-of-cycle enrichment spit can je approximated by

$$
\frac{r_{2}}{E_{1}} \text { (BOC optimum) }=\frac{1+\frac{1}{2} x_{1} T}{1+\frac{1}{2} x_{2} T} \times \exp a \exp \left(b \frac{v_{1}}{v_{2}}\right),
$$

where $T=$ length of the burn cycle. The factor $\left[1+\frac{1}{2} \alpha_{1} T\right] /\left[1+\frac{1}{2} \alpha_{2} T\right]$ in (6.6) is relatively insensitive to smal 1 variations in $\varepsilon_{2} / \varepsilon_{1}$ (BOC). For example, for $F V F=0.45$ and $V_{2} / V=0.30$, the two inputs $\varepsilon_{2} / \varepsilon_{1} \quad(B O C)=1.353$, and 1.421 yielded values of this factor of 1.0534 and 1.0545 , respectively Thus, a good estimate of the optimized $\varepsilon_{2} / \varepsilon_{1}$ (BOC) could be obtained from one burnup calcr lation and Eq. $(6.5)$ provided the first guess of $\varepsilon_{2} / \varepsilon_{1}(\mathrm{BOC})$ is reasonably good.

It should be emphasized that the methods and equations of this section are incended only as a way of obtairing a fafrly good estimate of the optimum enrichment split $\varepsilon_{2} / \varepsilon_{1}(B O C)$. Because of the great sensitivity of scrie burnup characteristics, it may be desirable to use it as a first gress input subject to more refinement.

VII. SUMMARY AND DISCUSSION

The Investigation of radial zonirg in a cylindtical model of an uncontrolled carbide reactor in the 5000 Mt class was carred out the zonting paranezers were the ratio of the oúter core volume to cotal core volume, denoted by $v_{2} / v$, and the racio of the outer to inner core fissile enrichment, $\varepsilon_{2} / \varepsilon_{1}$. 
Both static zoning and first-core burn cycle zoning were investigated. In the former, the optimum power peaking factor decreased with increasing fuel. volume fraction; the reverse trend occurs for burn-cycle zoning. Burn-cycle zoning also resulted in an increase in the optimum peaking factor and a shift to larger oftimum values of $v_{2} / V$ over the static zoning.

Since the rptimum radial power peaking factor exhioits a bruad minimum as a function of the ratio of the outer core to total core volume, the emphasis of :Le analysis was on determining the benavior of the optimum value of $\varepsilon_{2} / \varepsilon_{1}$ for a given ratio $V_{2} / V$. For fixed $V_{2} / V$, the power peaking factor is extremely sensitive to the ratio of outer to inner core enrichmencs.

An analytical approach was adopted and appiied first to the case of static zoning. Applying a one-group approximation to an idealized model of the core led to a simple phenomenological formula for optimum $\varepsilon_{2} / \varepsilon_{1}$ in terms of the volume split $V_{1} N_{2}$, given by Eq. $(3.19)$. Two parameters are invelved which are approximately Iinear functions of the fuel volume fraction.

Subsequenty it was shown that the expression also holds for the midczcle ratio of the volume-averaged enrichments, $\bar{\varepsilon}_{2} / \bar{\varepsilon}_{1}$. Since $\bar{\varepsilon}_{1}$ and $\bar{\varepsilon}_{2}$ change very slowly with burnup, extrapolation to the beginning-of-cycle optimum enrichment: spiit. $\varepsilon_{2} / \varepsilon_{1}$ can be estimated by means of Eq. (6.6), where the parameters $a_{i}, i=1,2$, a me oitained from burnup calculations.

One of the most significa.t results of the investigation is the sensitivity of the power distribution in the reactor during burnup to small changes in the ratio $\varepsilon_{2} / \varepsilon_{\mathrm{l}}$. The consequences of this behavicr, which becomes mote pronounced as the fuel. volune fraction increases is currently under investigation, but it is worthwile to point out here that it is important to take it into account when perforning any kind of burnup calculations. 
Finaily, a remark is in order concerning the emphasis of the report on determining the minimum power pealing as a function of the enrichment split $\varepsilon_{2} / \varepsilon_{1}$ for a given value of $V_{1} / V_{2}$. It is possible to derive an analytical expression for the ninimum radial power peaking factor in terms of $v_{1} / V_{2}$ (or $V_{2} / v$ ) using the idealizad model of Se:tion III. The phenomenological parameters involved could be obtained for the model core by methods similar to those employed in Section IV. The useiulness of such an expression, however, is limited by two factors: (1) the volumes of the outer and inner core vary discontinuously for actual reactors, and (2) the optimun radial power peaking factors are relatively insensitive to changes in $V_{2} / V$ in the optimum range $v_{2} / V \simeq 0.3$ to 0.4 
References and Footnotes

l. M. J. King and W. P. Sarthoij, "Radial Zoning of Large L.GBRs, Fart I." ANL-AFP-19.

2. L. C. Just, H. Henryson, II, A. S. Kennedy, S. D. Spaะz:, 3. J. Toppel, and P. M. Walker, "The System Aspects and Interface Data Sets of the Argonne Reactor Computation (ARC) System," ANL-7711 (1971).

3. A. P. Olson, "A liser's Manual for the Reactor Burnup Systen, REBUS-2," FRA-TM-ú2 (1974).

4. Upper limits of the neutron energies for groups 1 through 8 were 10 Mel, $1.287 \mathrm{MeV}, 0.369 \mathrm{MeV}, 98.0 \mathrm{keV}, 24.2 \mathrm{keV}, 8.05 \mathrm{keV}, 1.84 \mathrm{keV}$, and $0.214 \mathrm{keV}$, respectively. (The contribution oi the eighth energy group is generally 2 or 3 orders of magnitude smaller than tine leading contributors, and have not been included on the grapins of Figs. 5 and 21).

5. In Figs. 6 and 22 the enrichment $\varepsilon$ is defined as the fissile enrichment, i.e., $\varepsilon \equiv$ mass of fissile isotopes/mass of heavy metal.

6. The peak/avg power can be expressed as the product of the radial peak/avg power and the axial power peaking factor. The latter was calculated with the assumption of a cosine power distribution in the axial direction, and for the model reactor under consideration, is given by 1.2307 . 
Table I. Model of Carbide-Fueled Reactor

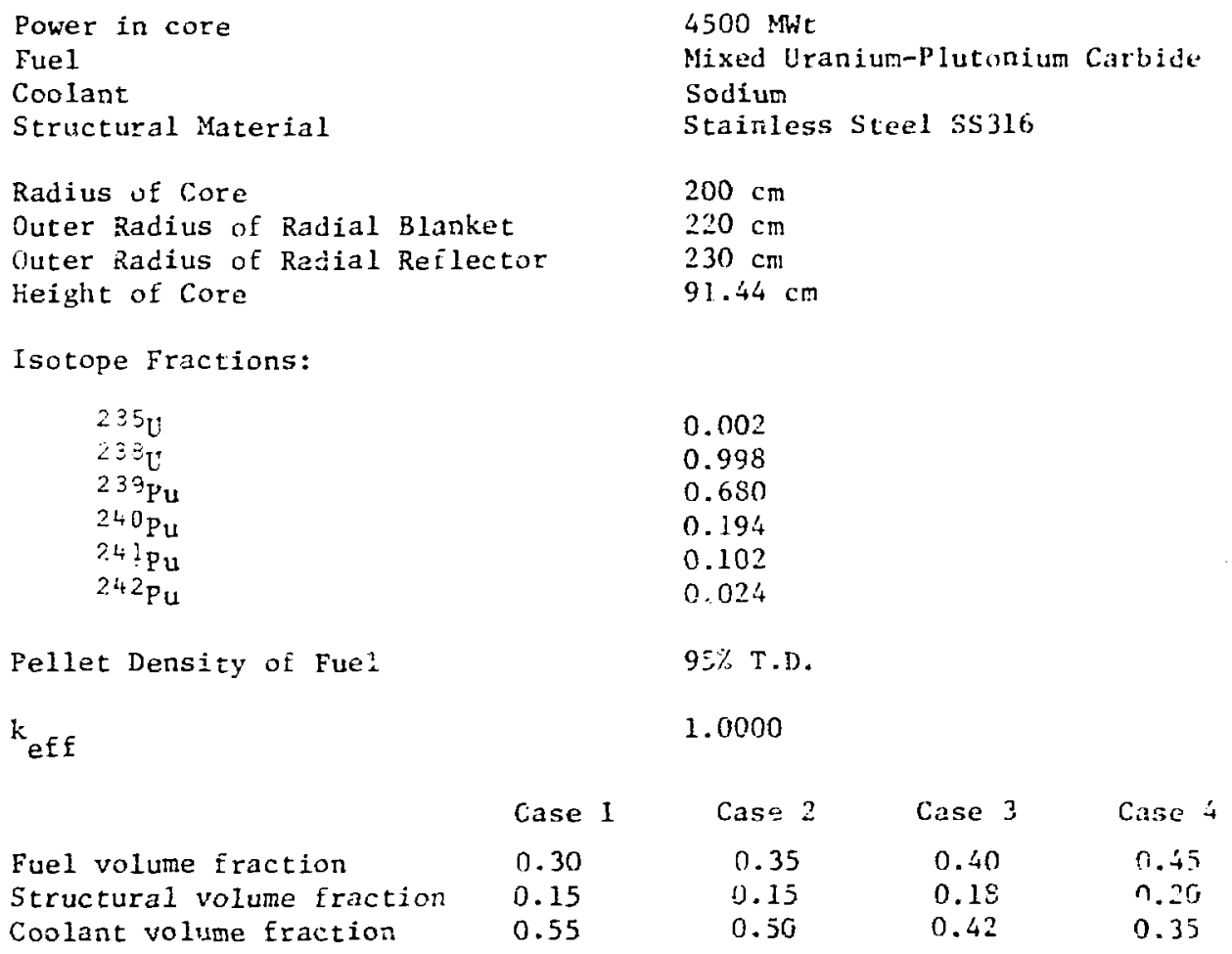


Table II. least Squares Solutions for Parameters a and b

$$
\begin{aligned}
& \text { in } \varepsilon_{2} / \varepsilon_{1}(\text { static opt })=\exp \text { a } \exp \left(b v_{1} / v_{2}\right) \\
& \text { for the Model Carbide Corc of Table }{ }^{(a)}
\end{aligned}
$$

\begin{tabular}{|c|c|c|c|c|}
\hline $\begin{array}{l}\text { Pellat } \\
\text { Density } \\
\text { of Carbide } \\
\text { Fuel (PD) }\end{array}$ & $\begin{array}{l}\text { Fuel } \\
\text { Volume } \\
\text { Fraction } \\
\text { (Fif) }\end{array}$ & $\begin{array}{l}P D^{*} F V F \\
(T . D .)\end{array}$ & a & $\mathrm{b}$ \\
\hline \multirow[t]{4}{*}{.95 T.D. } & 0.30 & 0.2850 & $0.039 \angle 9$ & 0.3270 \\
\hline & 0.35 & 0.3325 & 0.02953 & 0.1205 \\
\hline & 0.40 & 0.3800 & 0.02028 & 0.1114 \\
\hline & 0.45 & 0.4275 & 0.01373 & 0.1031 \\
\hline
\end{tabular}


Table III. Comparison of Midcycle Enrichment Splits for Optinized First-Core Burn Cycles and Static-Zoning Optimized Enrichment Splits

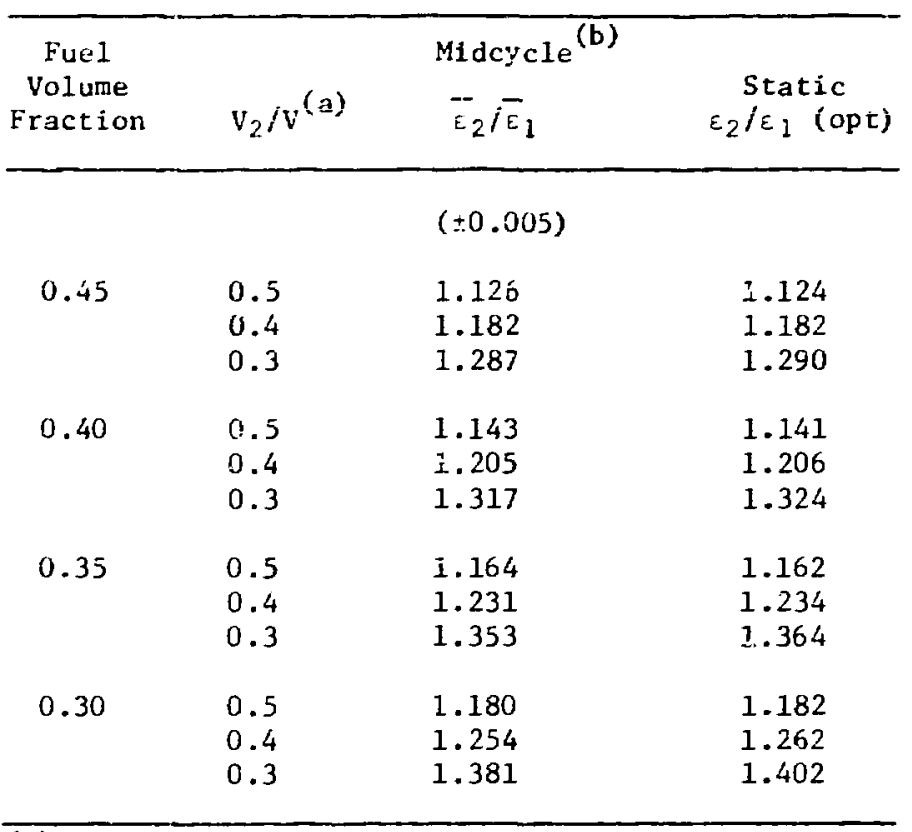

(a) Outer core to total core volume ratio.

(b) $\bar{\varepsilon}_{2} / \bar{\varepsilon}_{1}$ is the ratio of the outer-core average enrichnent to inner-core average enrichment at 150 days. 


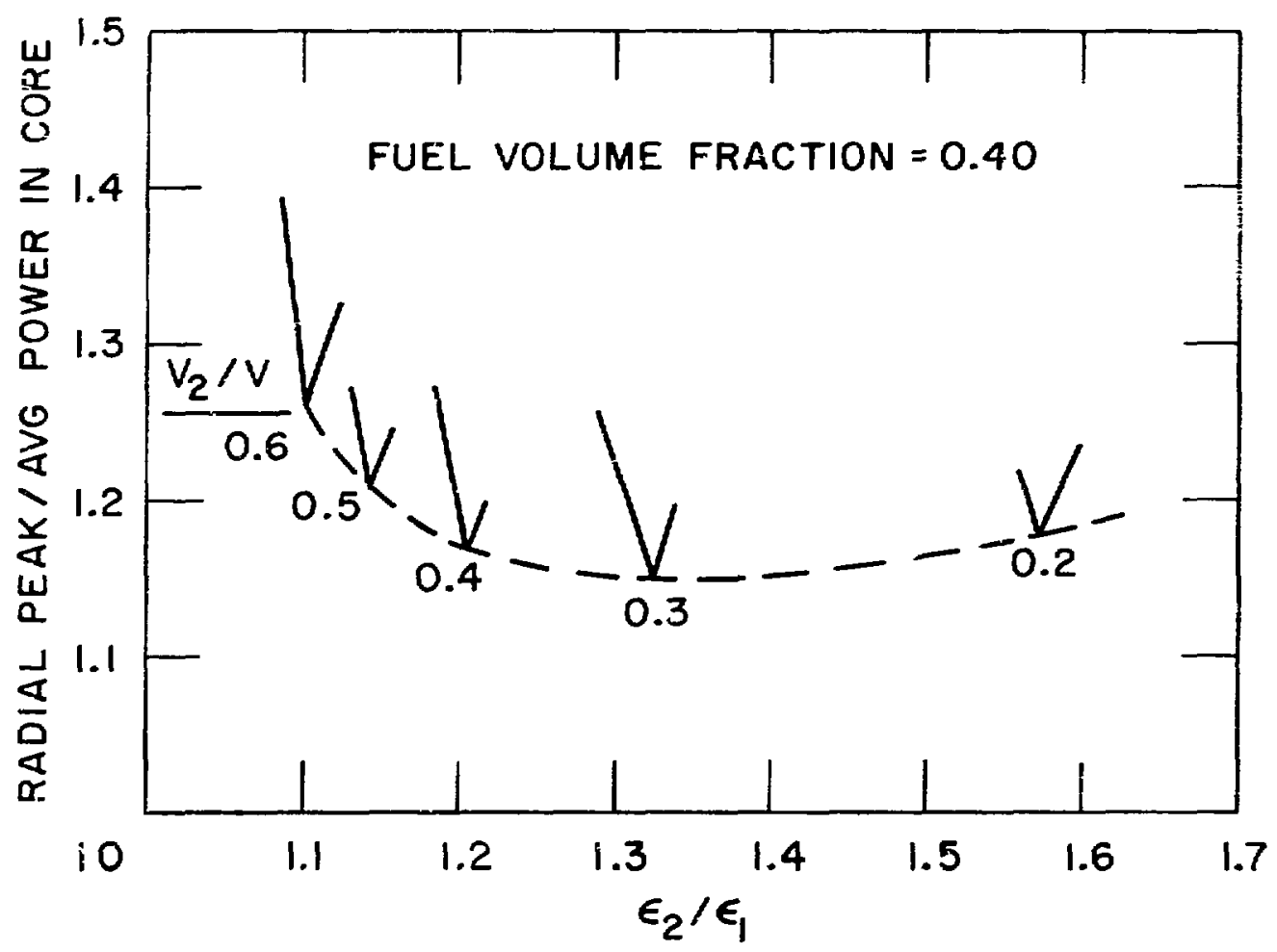

Fig. 1. Radial power peaking factor as a function of enrichment split for static (beginning-of-cycle) conditions. First and second legs of the "vees" correspond to the porver peak occurring in the 1 nner and outer core, respec-
tively. 


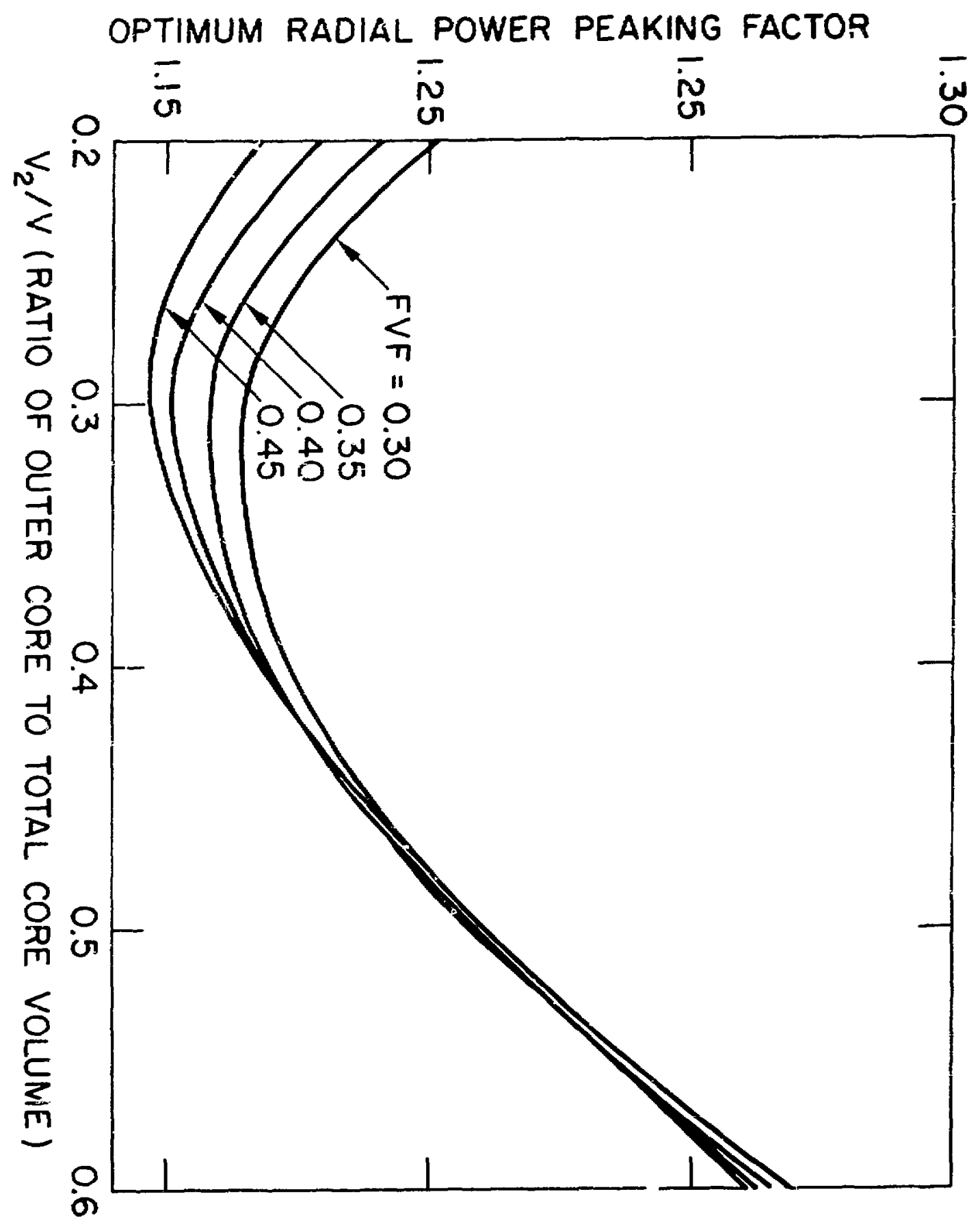

lig. 2. Optimum radial power peaking factor as a fumction of outer core volume for static (begiminb-of-cycle)

condit:ass and fuel volume fractions $11.30,0.35,0.40$, 0.45 . 


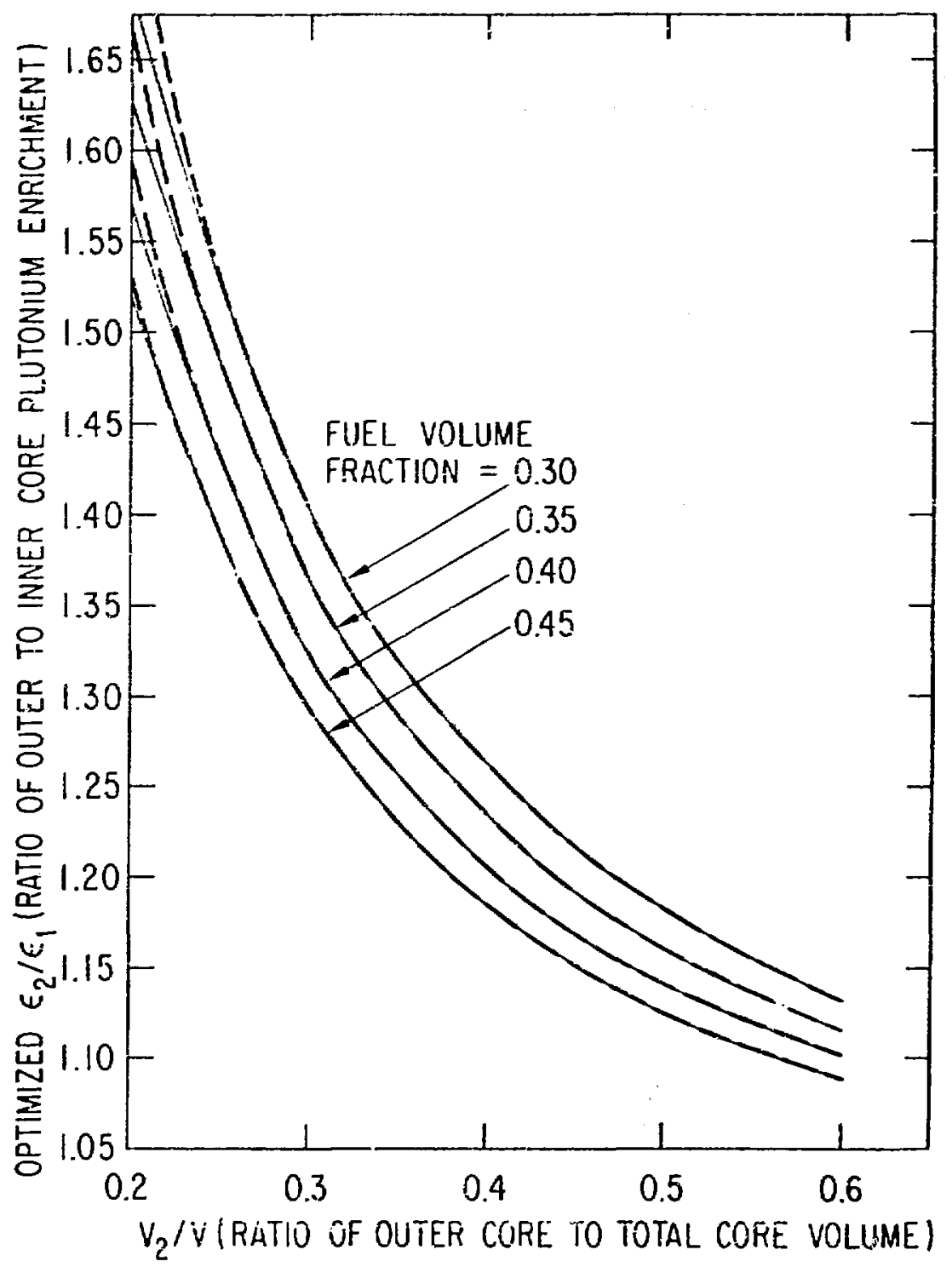

Fig. 3. "ptimized beginning-ef-cycle enrichment split $c_{2} / t_{2}$ as a iunction of outer core volume for static (beginning-ot$\because \because \mathrm{cle})$ conditions. The dashed lines correspond to solutions . $f \varepsilon_{2} / \epsilon_{1}=\exp$ a exp (b $\frac{v_{1}}{V_{2}}$ ), where parameters a and $b$ are determined in Section IV. 


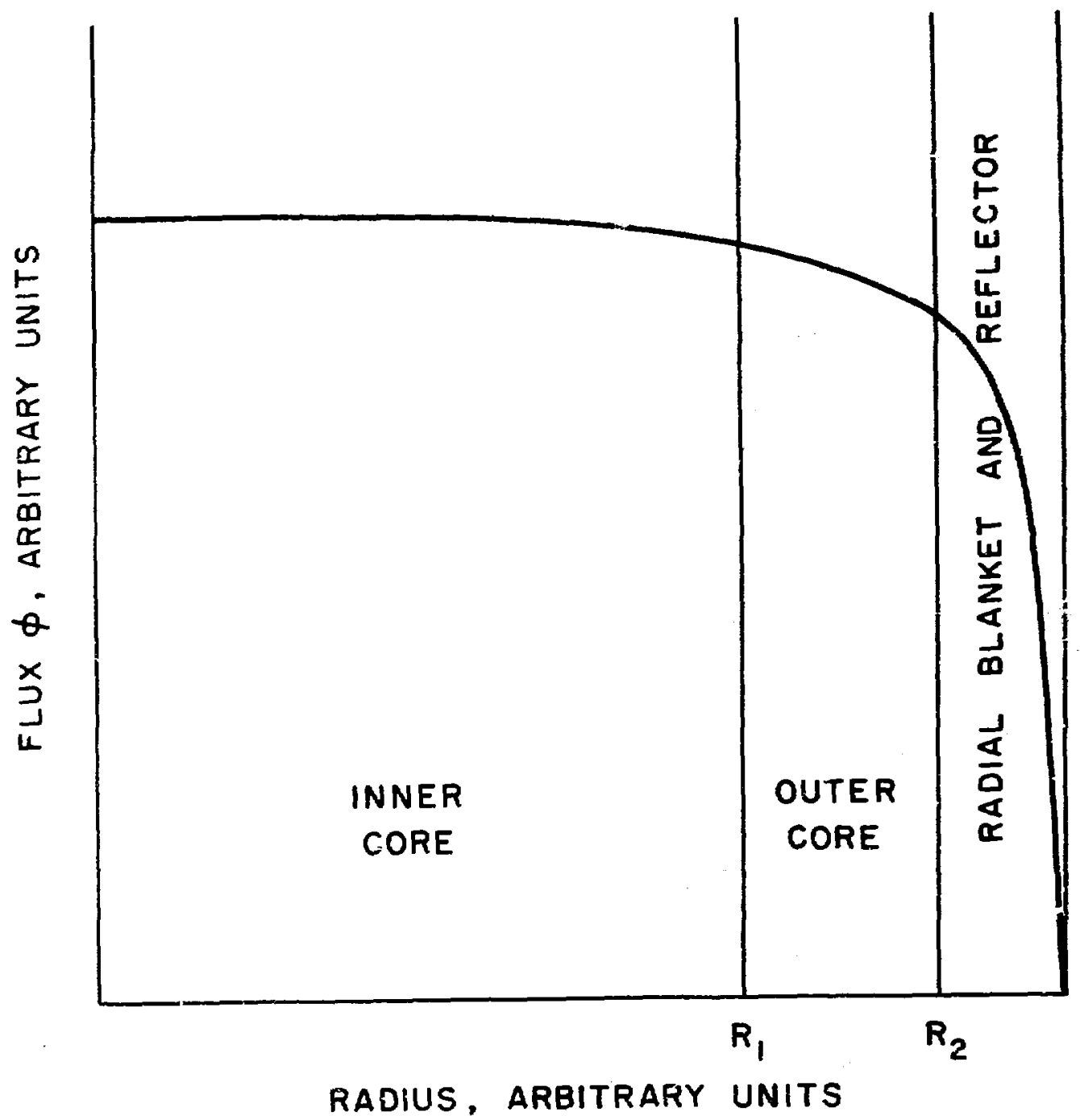

Fig. 4. Schematic 1llustration of radial flux distribution in the cylindrical model reactor described in Section III. 


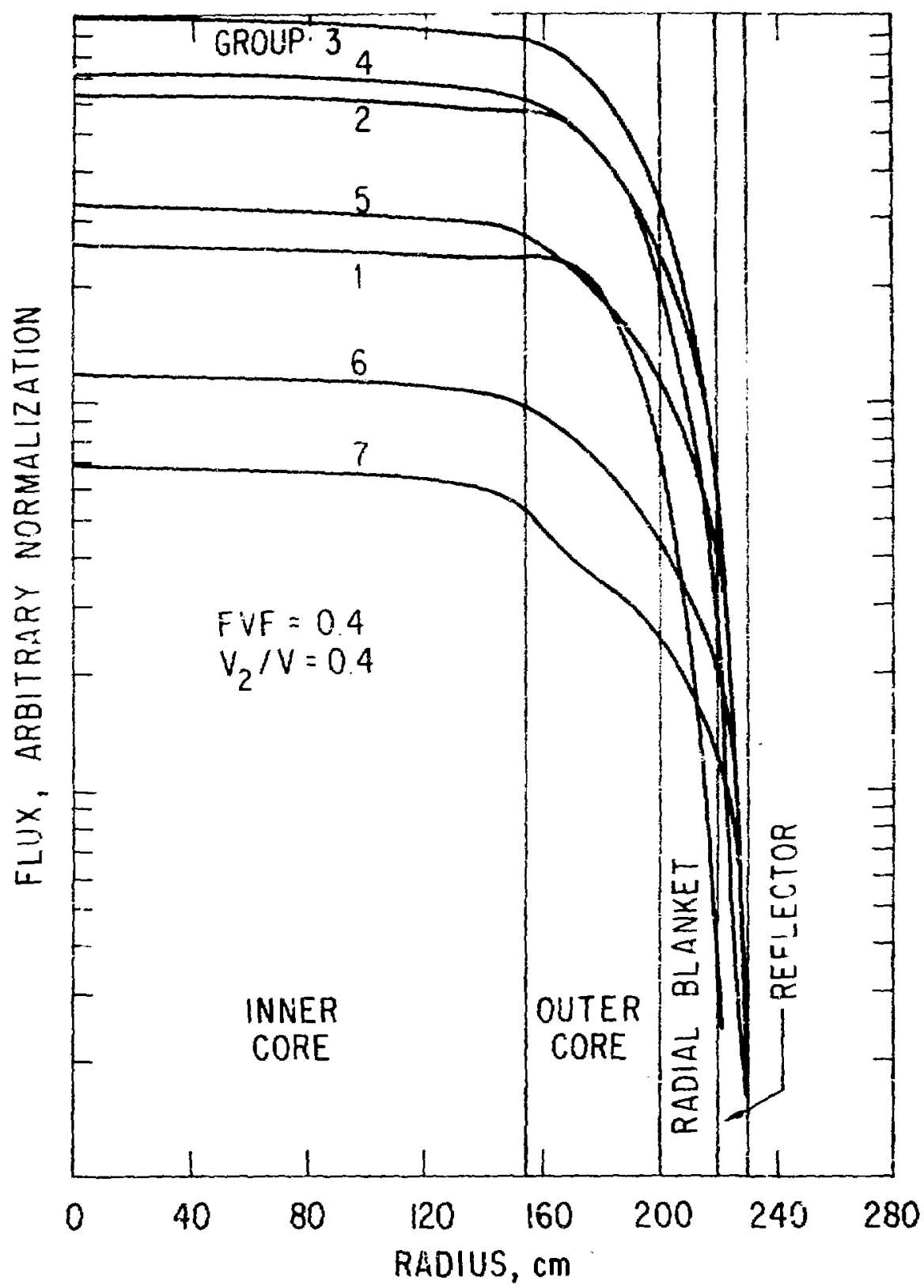

Iig. 5. Radial flux distribution for seven eiergy groups ${ }^{4}$ for the case fuel volume fraction $=0.4$, outer-to-totai core volume $=0.4$, and optimum enrichment split $=1.2055$. The static (beginning-of-cycle) power peaking factur has been minimized for the given ratio of outer to total core volume. 


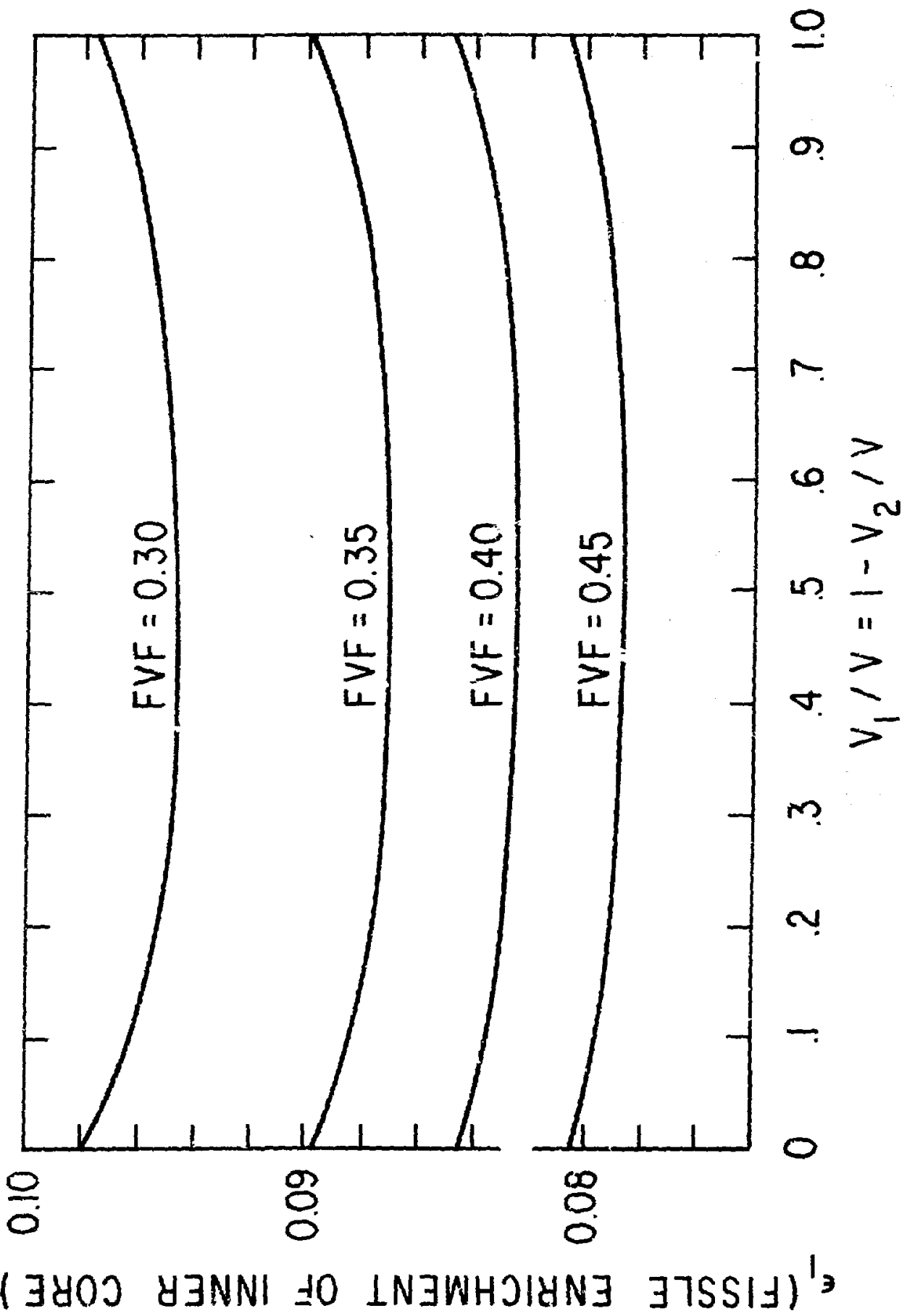

Fig. 6. The fissile enrichment ${ }^{5}$ of the inner core, $\varepsilon_{1}$, vs. the ratio of inner core to totai core volume, $v_{2} / v=1-v_{2} / V$, for four fuel voluthe fractions $0.30,0.35,0.40,0.45$. The enrichment split $\varepsilon_{2} / \varepsilon_{1}$ was optimized as a function of $v_{1} / v_{2}$. 


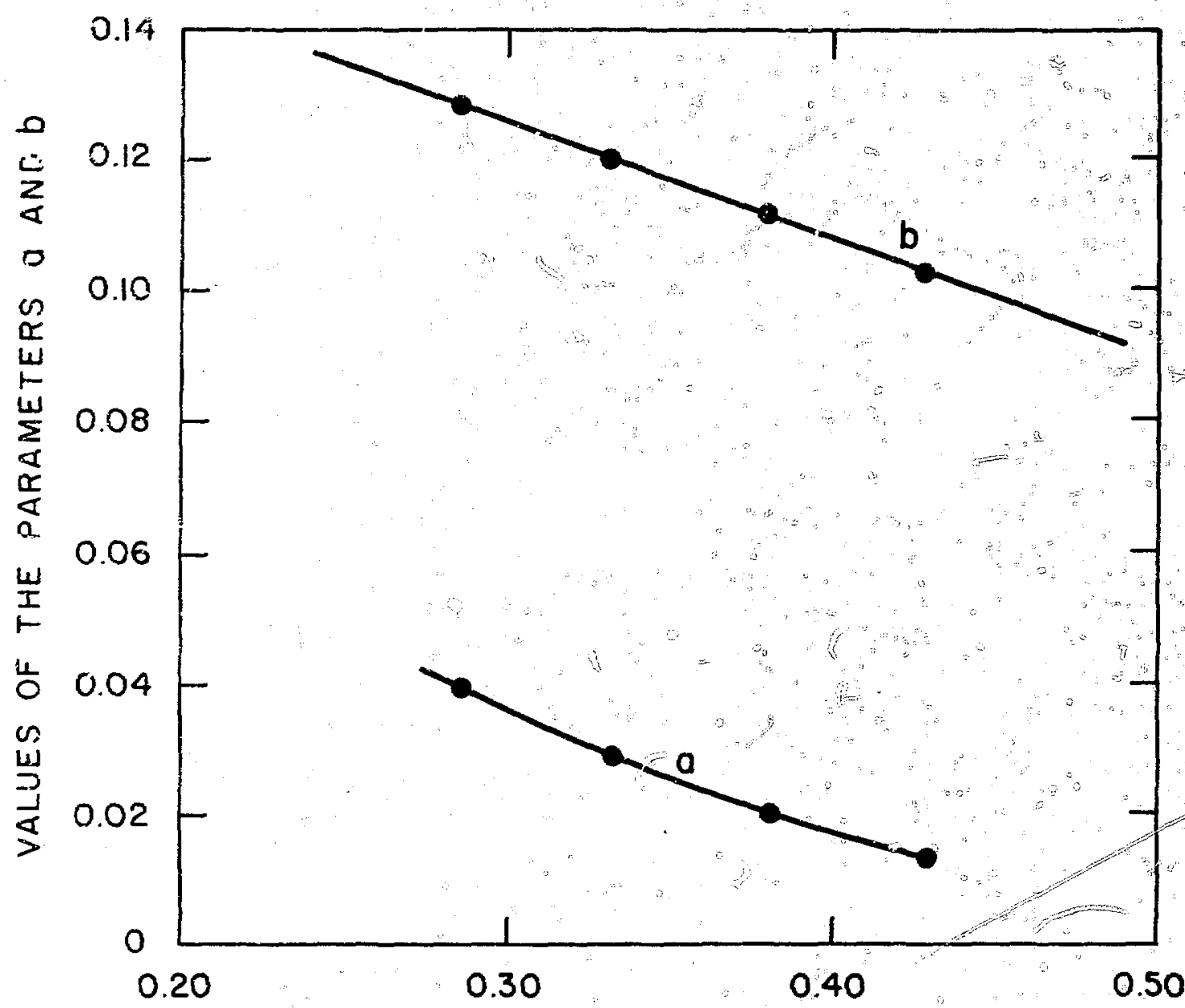

$F \vee F * P D$

Fig. 7. The parameters a and b, determined in section Iy by ?east squares fit to the equation $E_{2} / c_{1}$ (static optimum) :$\exp$ exp (b $\left.V_{1} / V_{2}\right)$, versus the froduct of the fuel voluthe fraction (FVF) and the pellet density (PD) of the fuel (oD is the fraction of the theoretical density). 


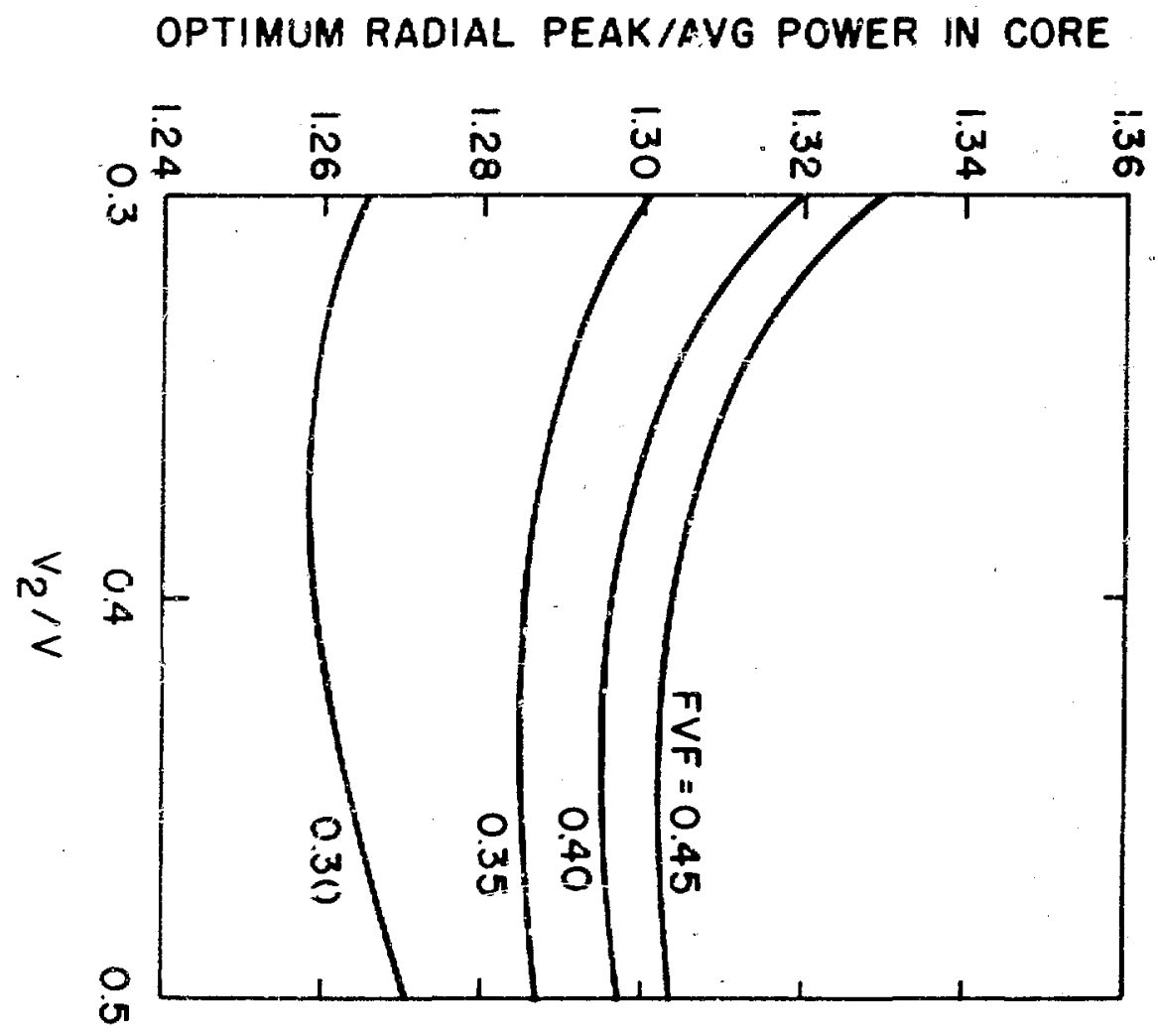

Fig. 8. Optimum radial power peaking factor as a function of outer core volume for a burn cycle of 300 days corresponding to first-core loading. Four fuel volume fractions are considered, $0.30,0.35,0.40$, and 0.45 . 


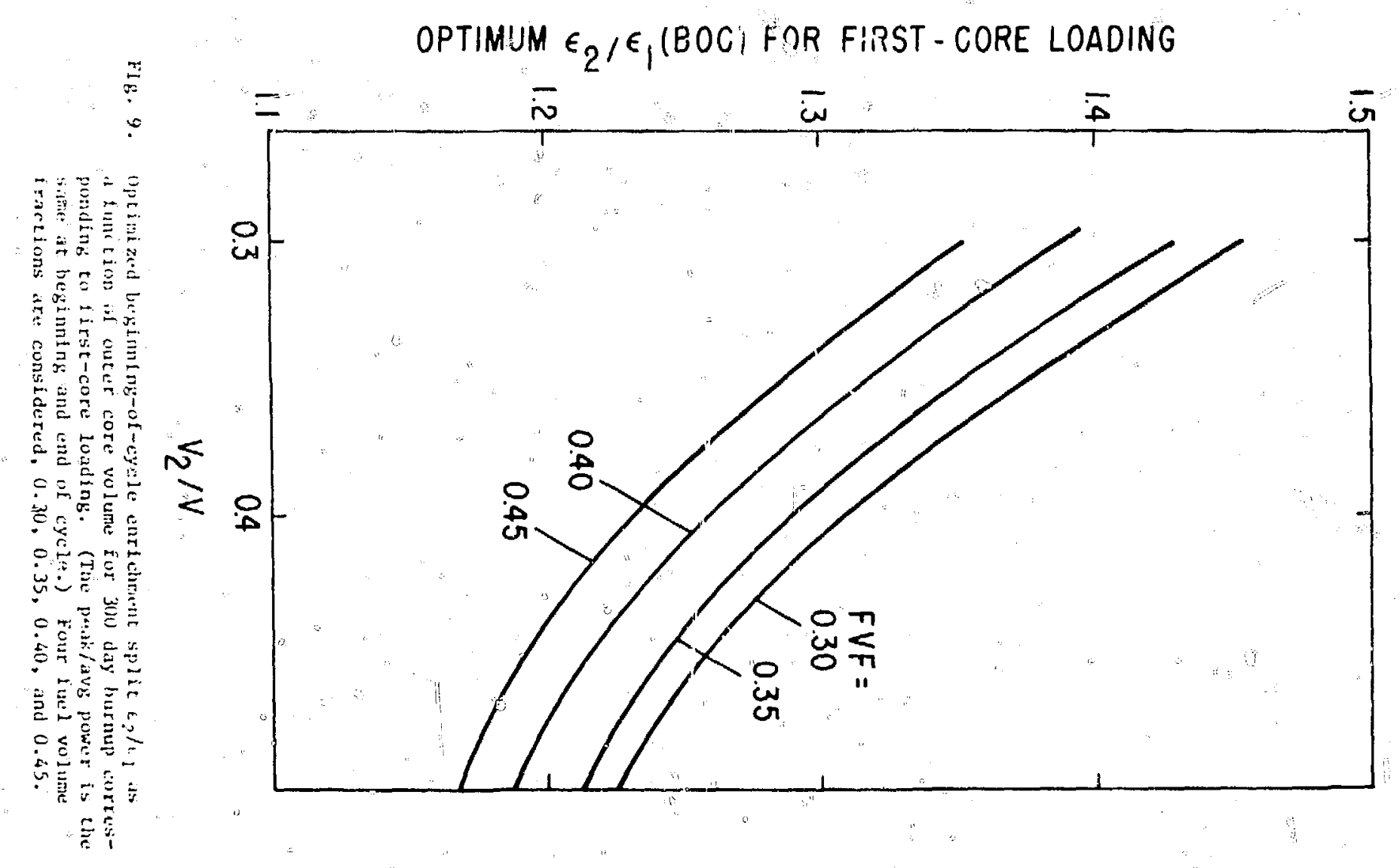




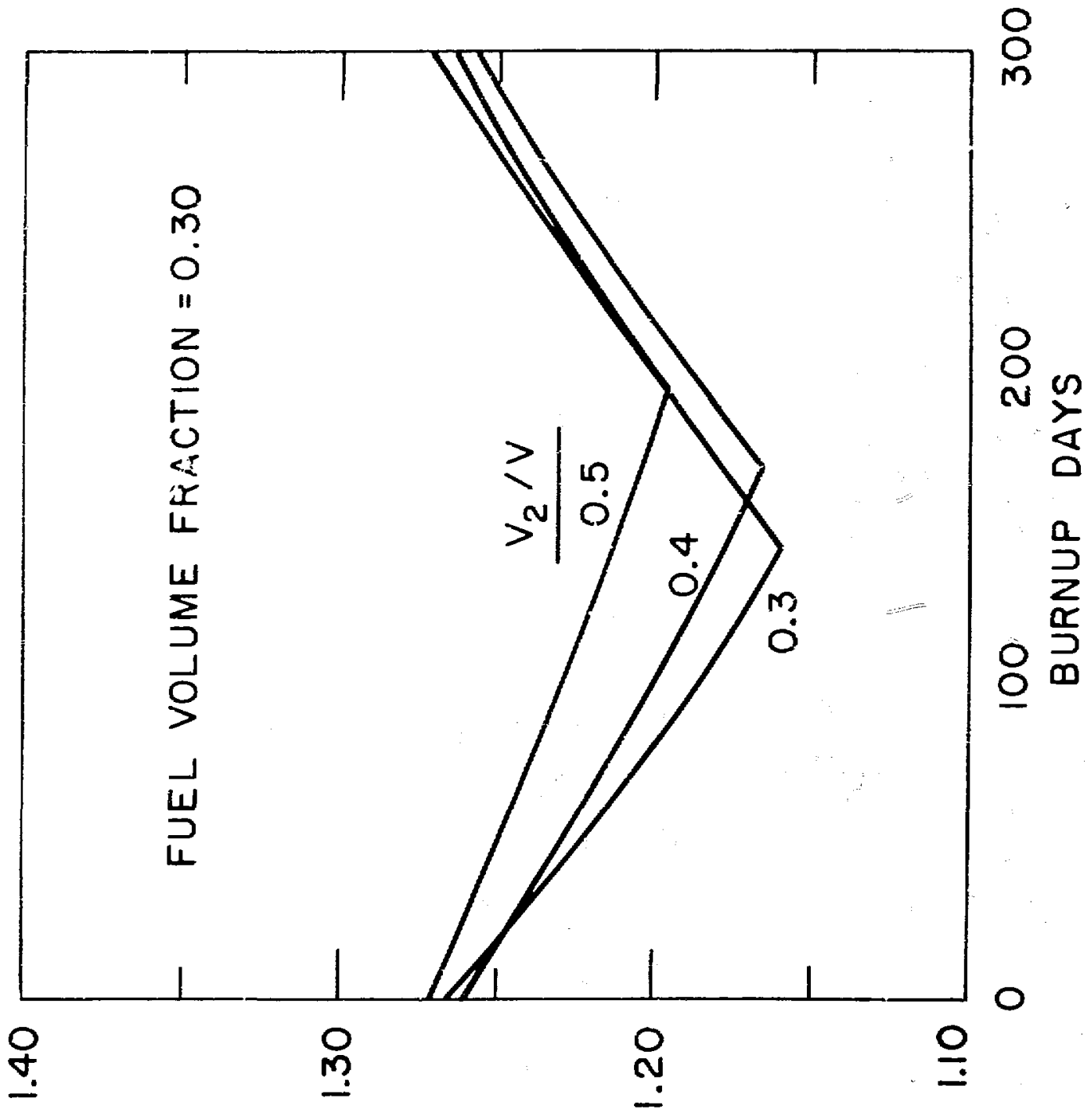

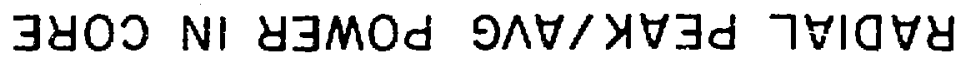

H12. 10. The radial peak/avg power as a function of burnup days in a 300 day burn cyste corresponding to first-core loading and fue 1 volume fraction 0.30 . Three ratios of outer core to cotal core volume, $v_{2} / V=0.3,0.4,0.5$, are considered. 


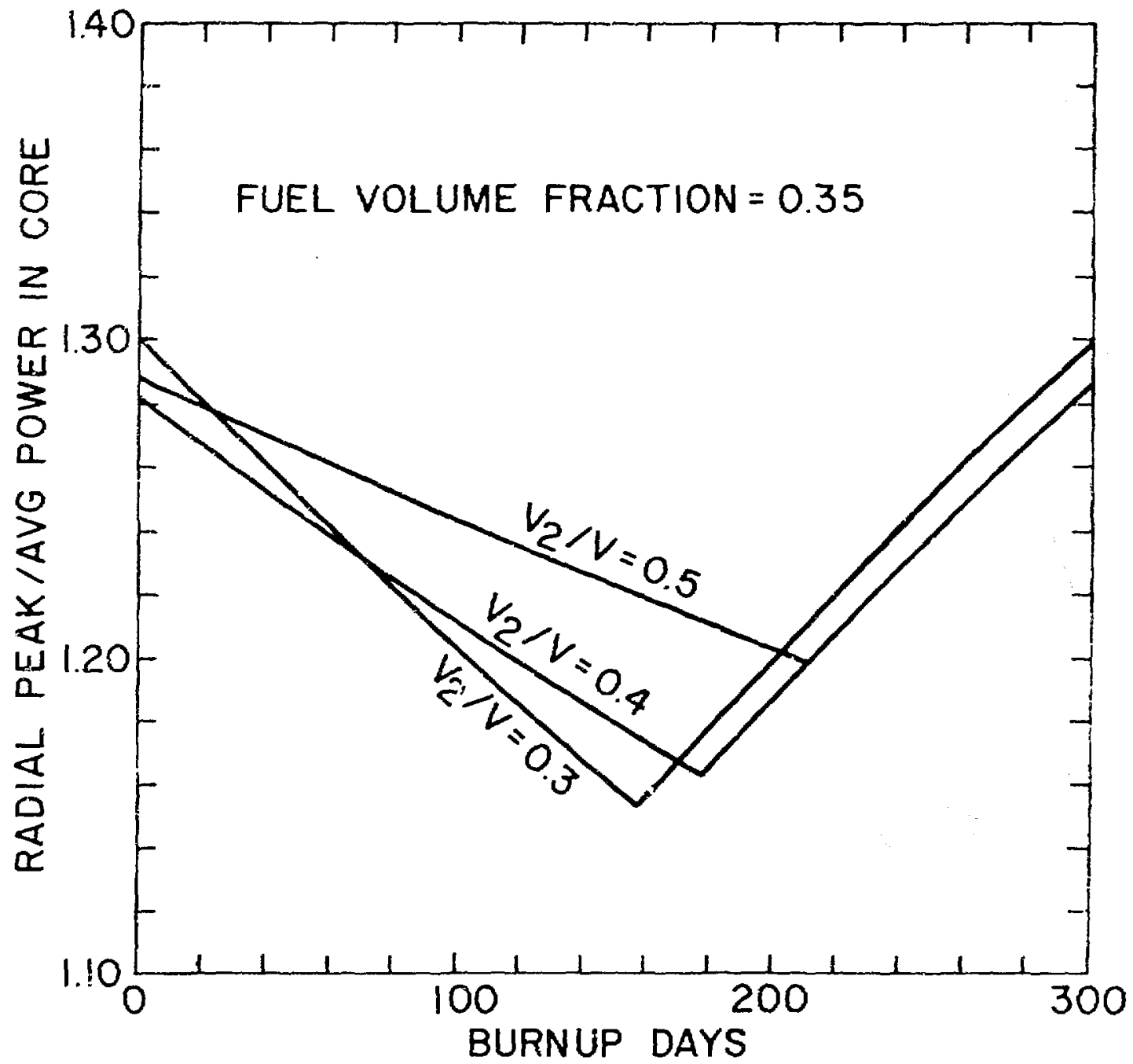

Fig. 11. The radial peak/avg power as a function of burmug dims in a 300 day burn cycle corresponding to first-core loadinti and fuel volume fraction 0.35 . Three ratios of viter core to total core yolume, $V_{2} / V=0.3,0.4,0.5$, are considered. 


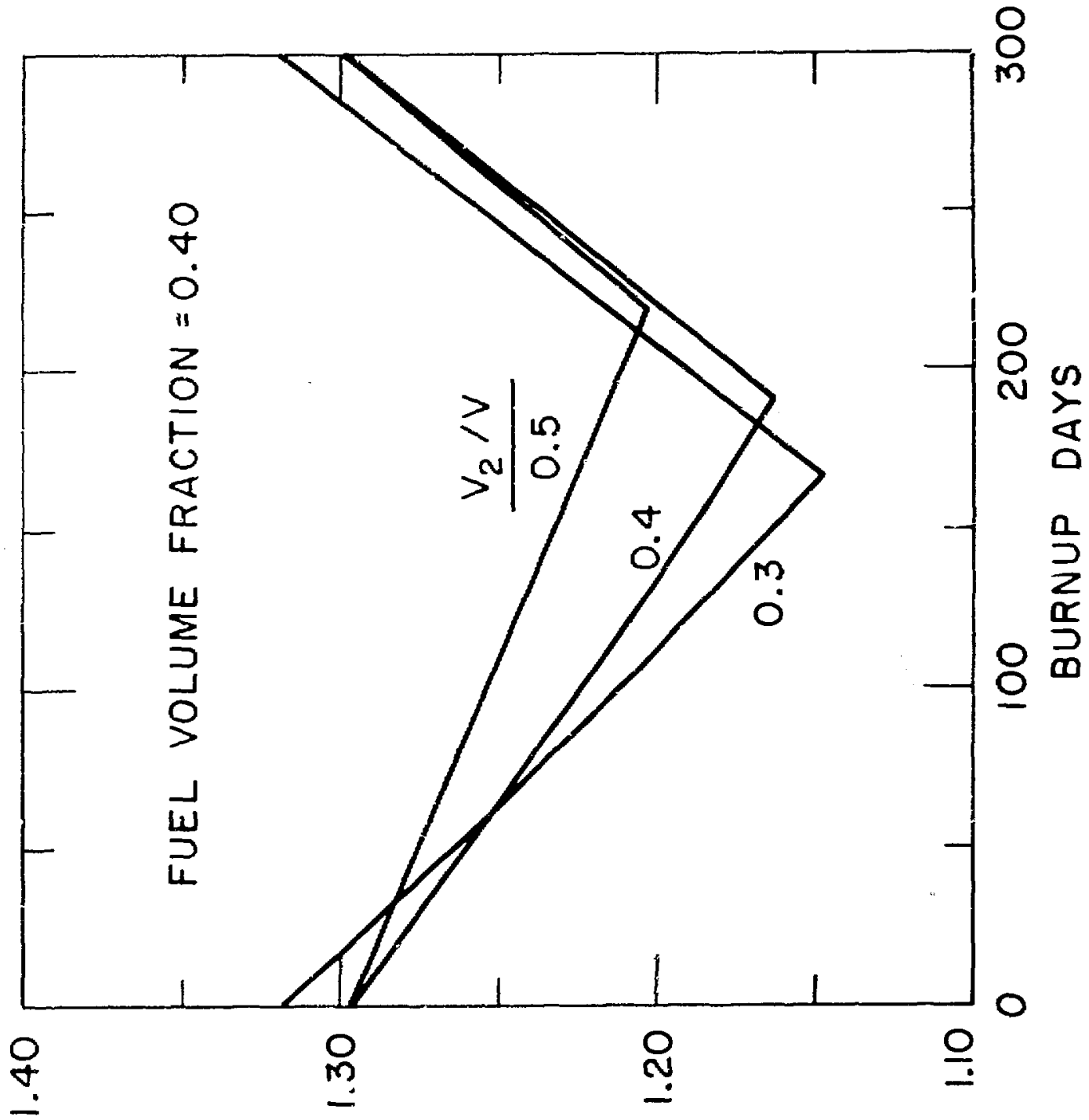

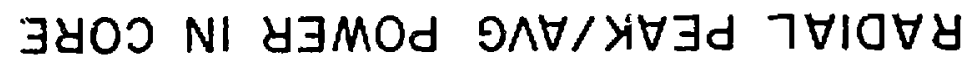

Fig. 12. The radial peak/avg power as a function of burnup days in a 300 day burn cycle corresponding to first-core loading and fuel volume fraction 0.40 . Three ratios of outer core to total core volume, $v_{2} / V=0.3,0.4,0.5$, are considered. 


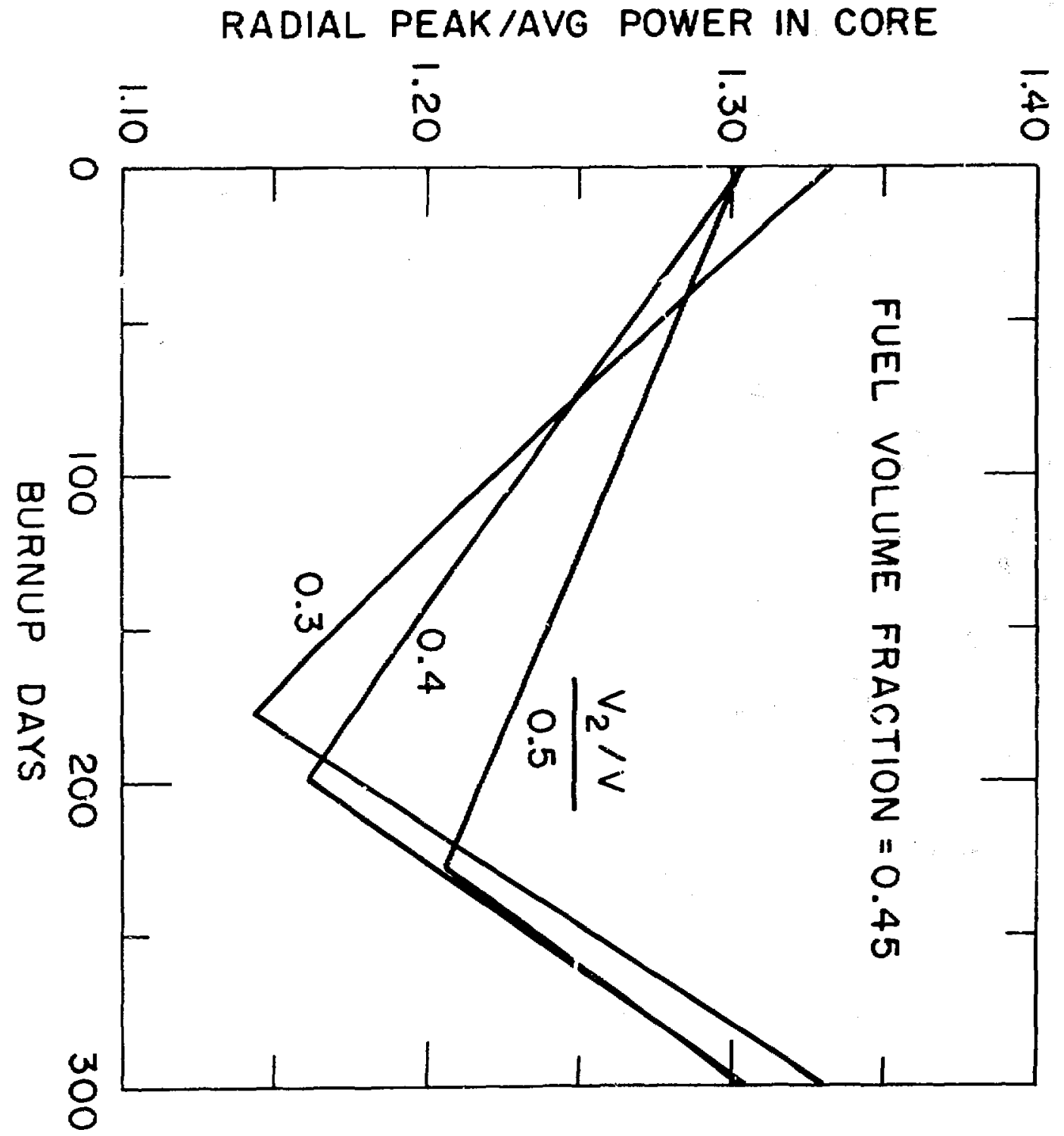

1

Fig. 13. The radial peak/avg power as a function of burnup days in a 300 day burn cycle correspondlng to first-core loading and fuel volume fraction 0.45 . Three ratios of outer core to total core volume, $v_{2} / v=0.3,0.4,0.5$, are considered. 
Hag. 14. Peak rission densities in inner and outer cores piotceit as a function of burnup days in a 300 day burn cycle corresponding to first-core loading and fuel volume fiaction 0.40. Three ratios of the outer to total cors volume, $v_{2} / v=0.3,0.4$, and 0.5 wert considered. Tha intersection of eaci pair of curves corresponis to tiut thinimum in the peak/avg power displinyed in $\hat{i}$ ig. 12.

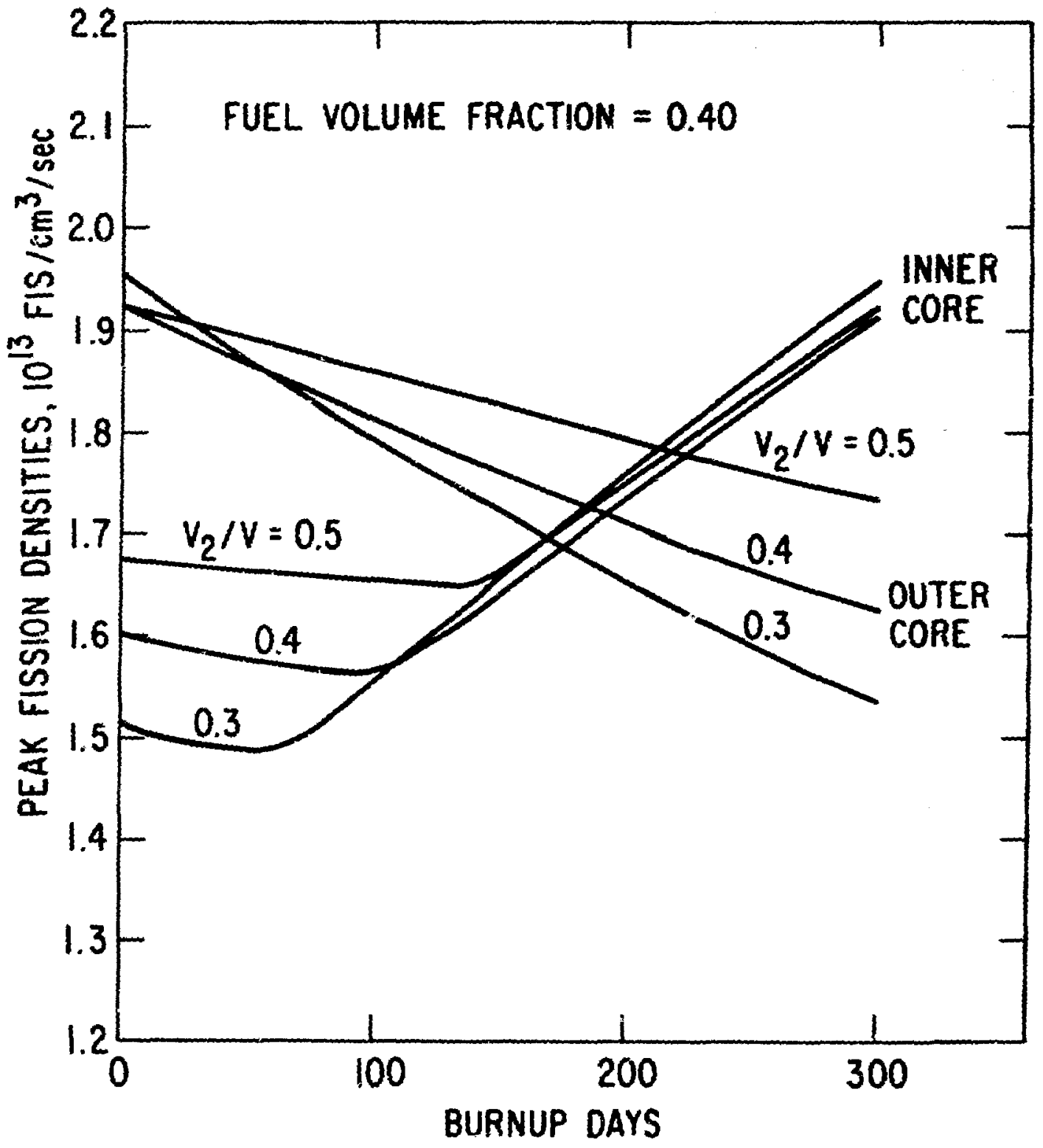




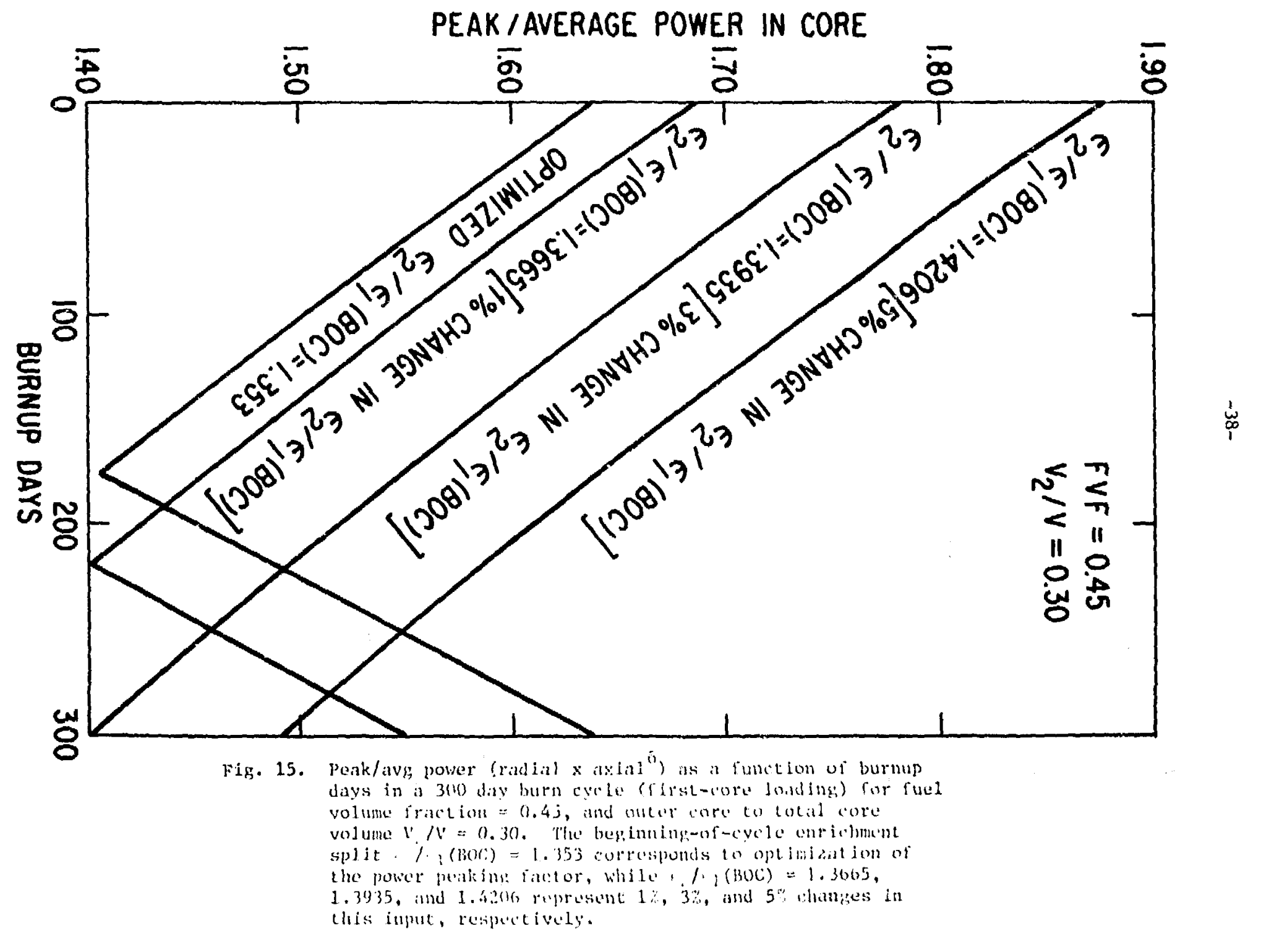




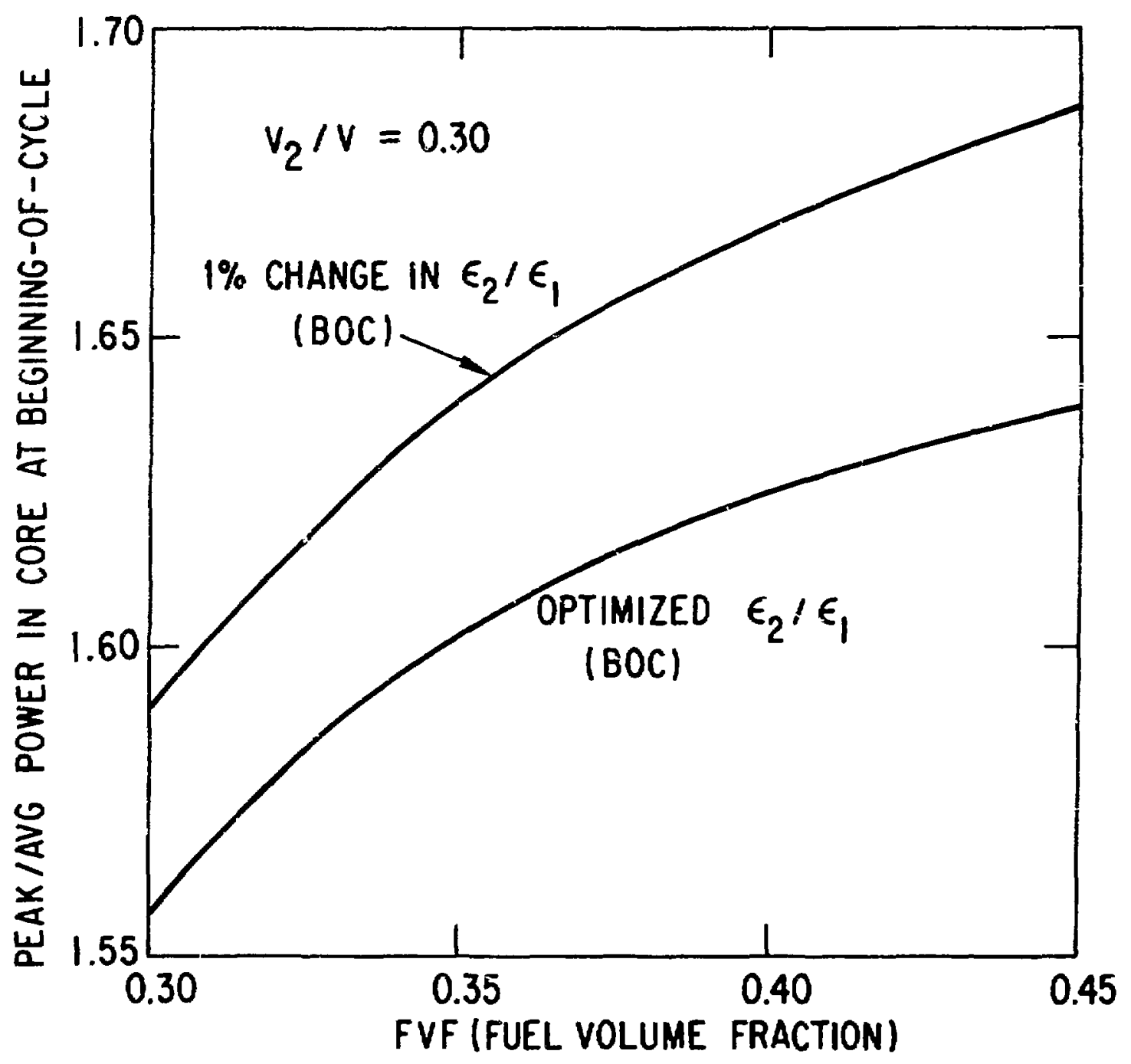

Fig. 16. Peak/avg power (radial $x$ axial) vs. fuel volume fraction for a 300 day burn cycle and ou'er cort to total core volume $V_{2} / V=0.30$. The lower curve shows the change $f$ in this factor if the beginning-of-cycle enrichment split is varied by $1 \%$ from tne optimum. 


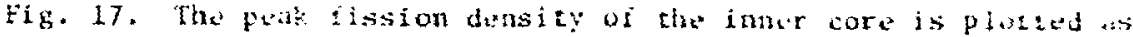
a funcliam of burnup days in a 300 day burn elyele (firsicure lonting). The begining of-kycle anriefone siplit

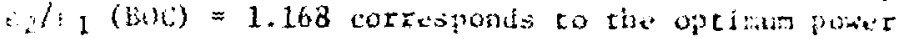
Puiking saceor for the givan voluthe split, $Y / Y=0.5$, and fuet volume fraction $=0.45$.

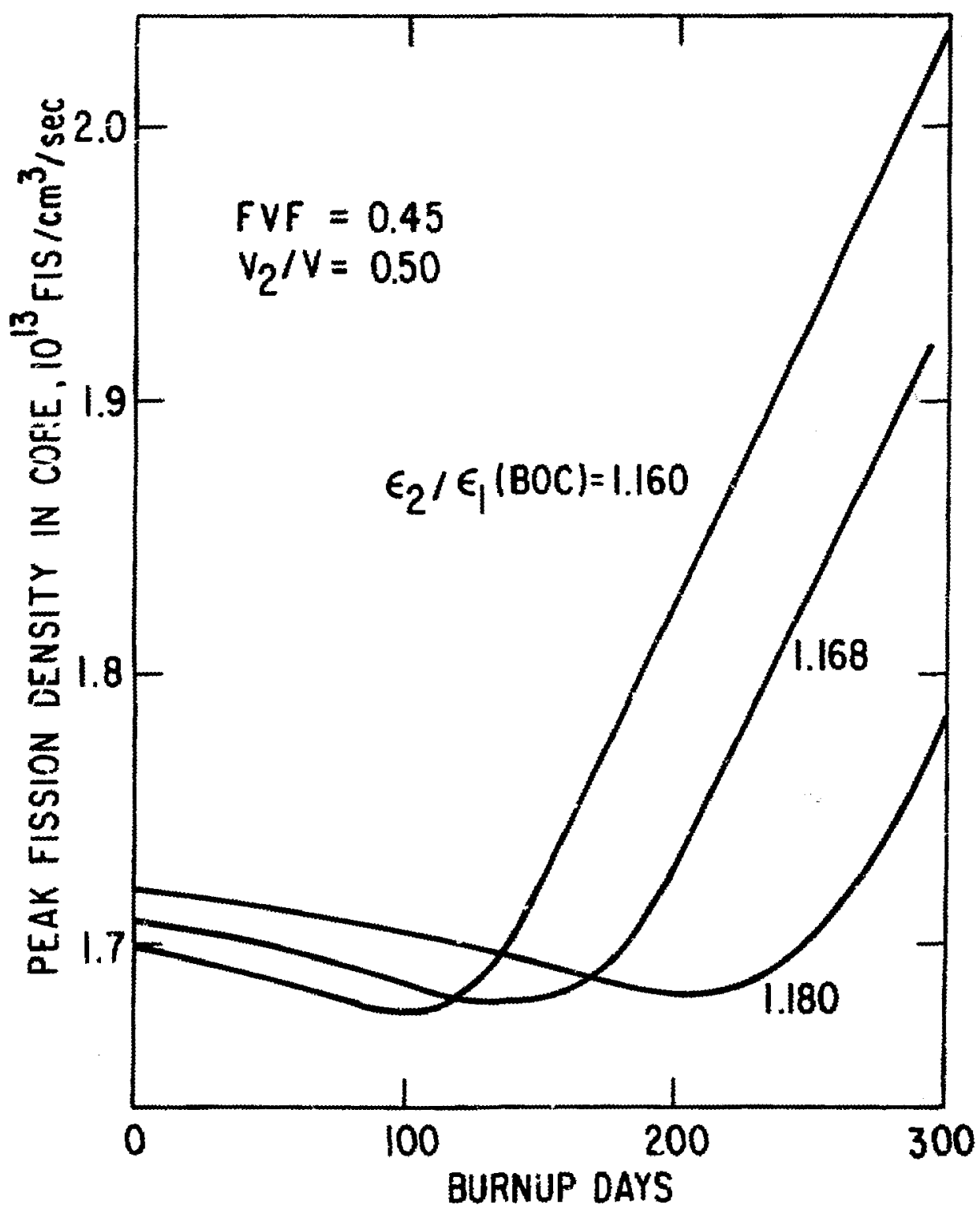




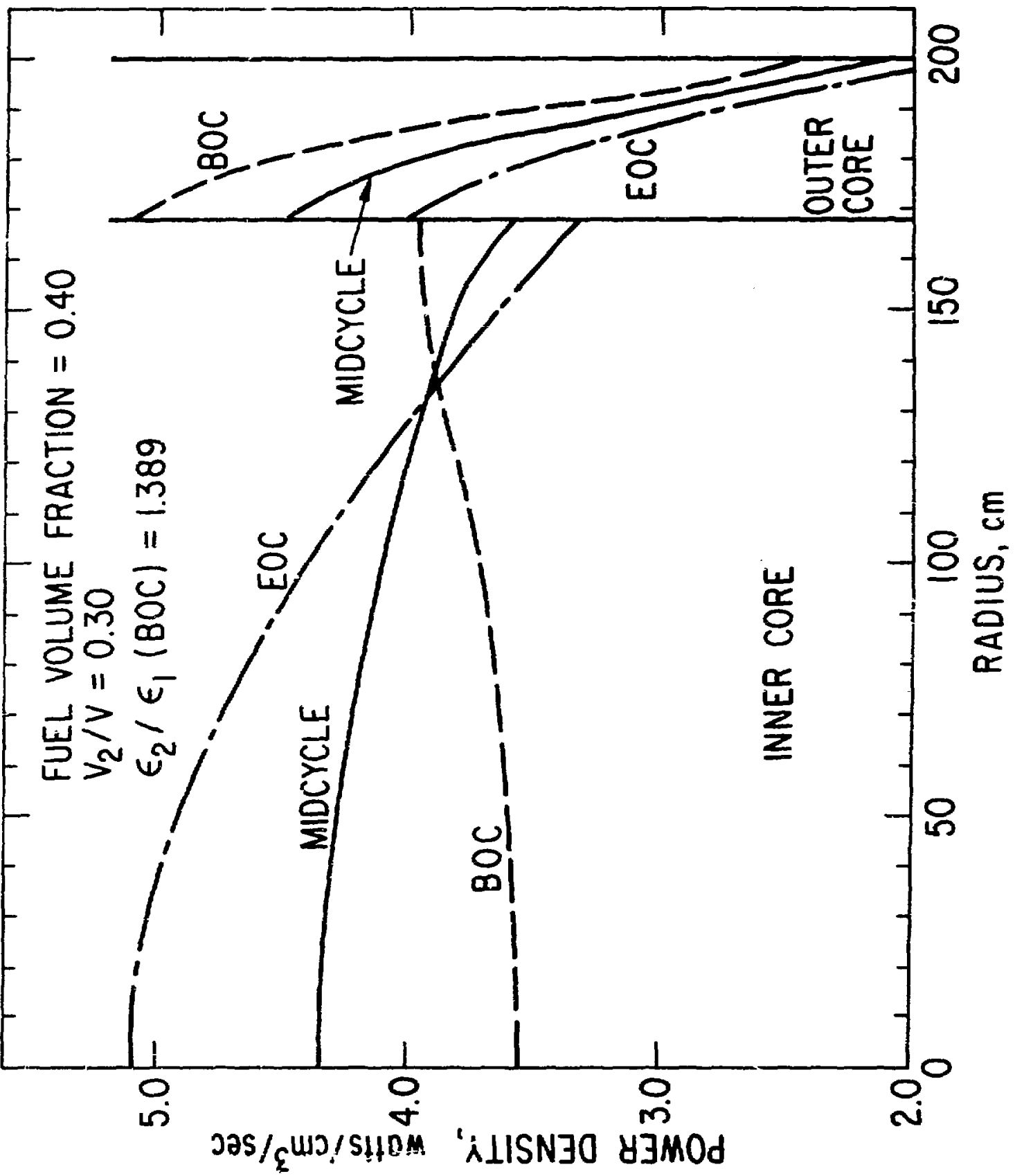

Fif. 18. The power density vs. radius of the core at beginning-of-cvcle (BOC), midcycle, and end-of-cycle (EOC). The beginning-of-cycle enrichment split $r_{2} / \varepsilon_{2}(\mathrm{BOC})=$ 1.389 corresponds to the optimum power peaking factor for the 300 cav burn crelc for the given volume split $v_{2} / V=0.30$ and fuel volume fraction $=0.40$. 
Fig. 19. The midcycle (150 days) tatio of tite awerabe miter cure cit$r$ icimenc to averabe inner core enrichtent, $\bar{E} \bar{L}_{i}$, as a iunction of the volume split $V_{2} / t$ ior four fiar 1 volue. iractioss. The dashed eurves are solutions $-\sqrt{1},($ a d d yeje $)=$

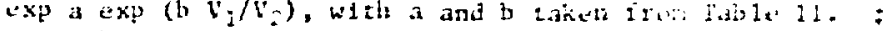

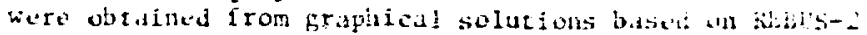
calculat $i$ ons and correspond to burnup optimiatlon of the power peitring factor.

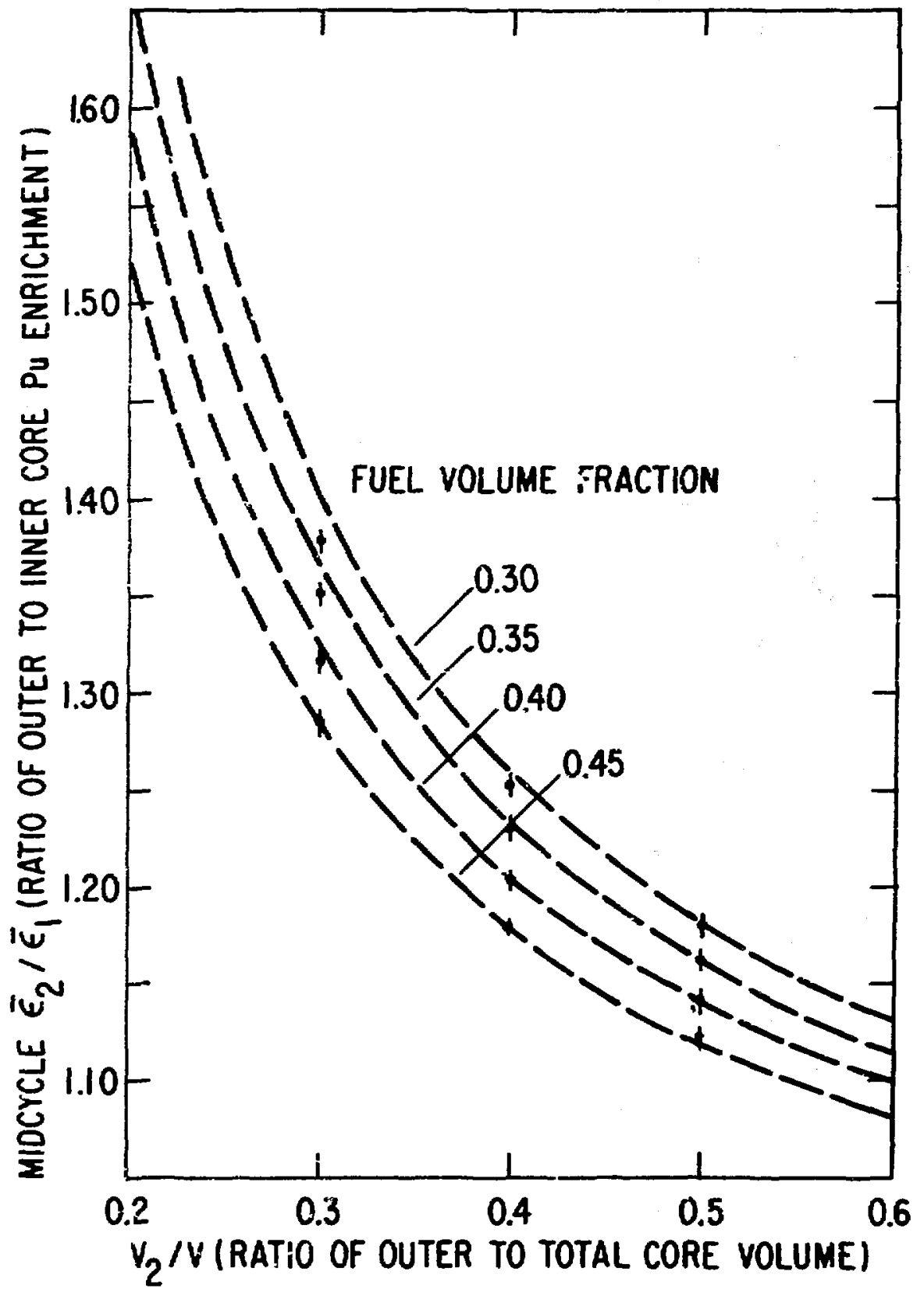




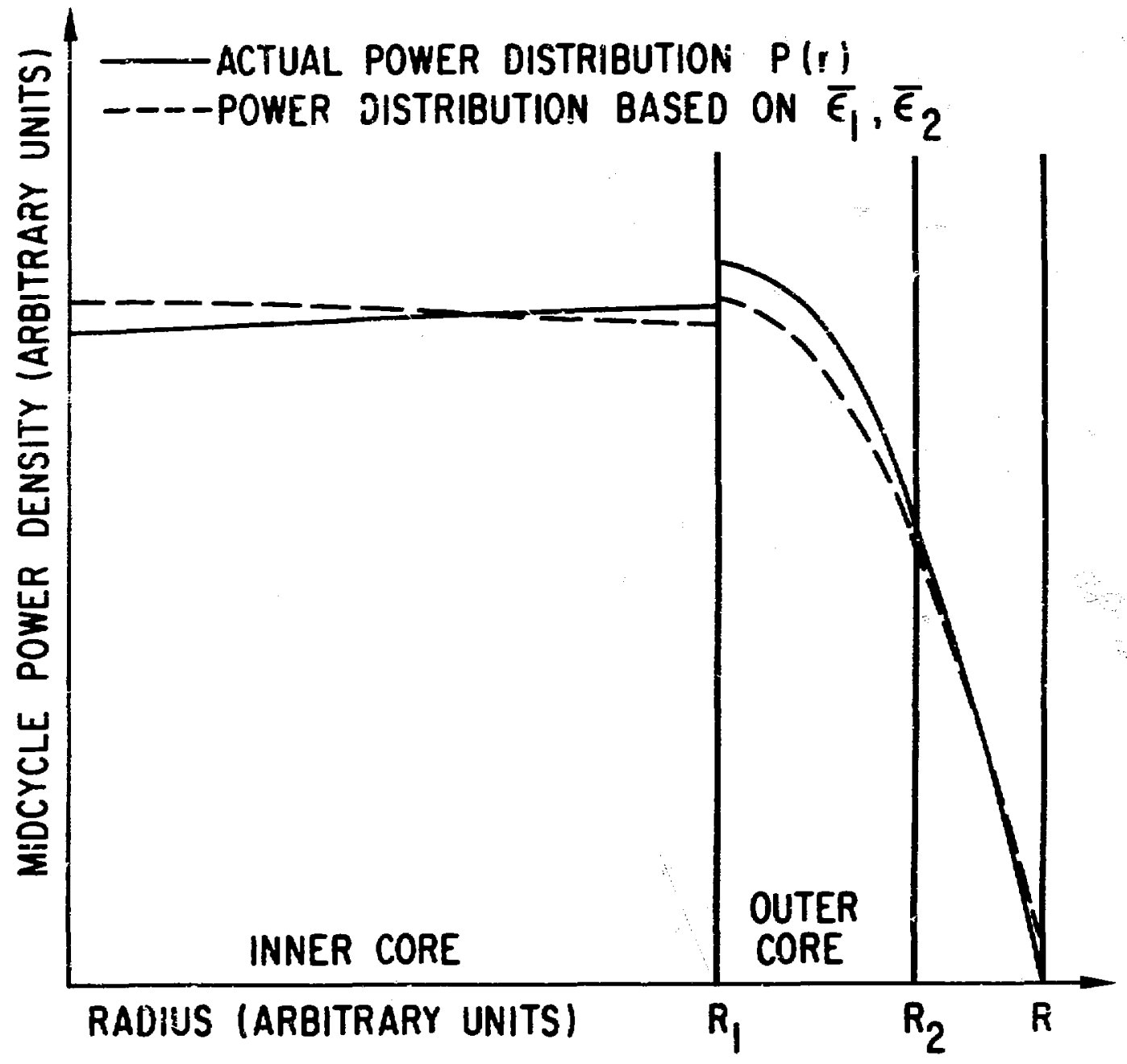

Fig. 20. Schematic plot of midcycle power distribution for optimized beginning-of-cycle enrichment split (burn cycle optimization). The solid line corresponds to actual power distribution, while the dashed line corresponds to a power distrilution which vould result from uniform enrichments $\bar{E}_{1}$ and $\bar{\varepsilon}_{2}$ in the inner and outer cores, respectively. 


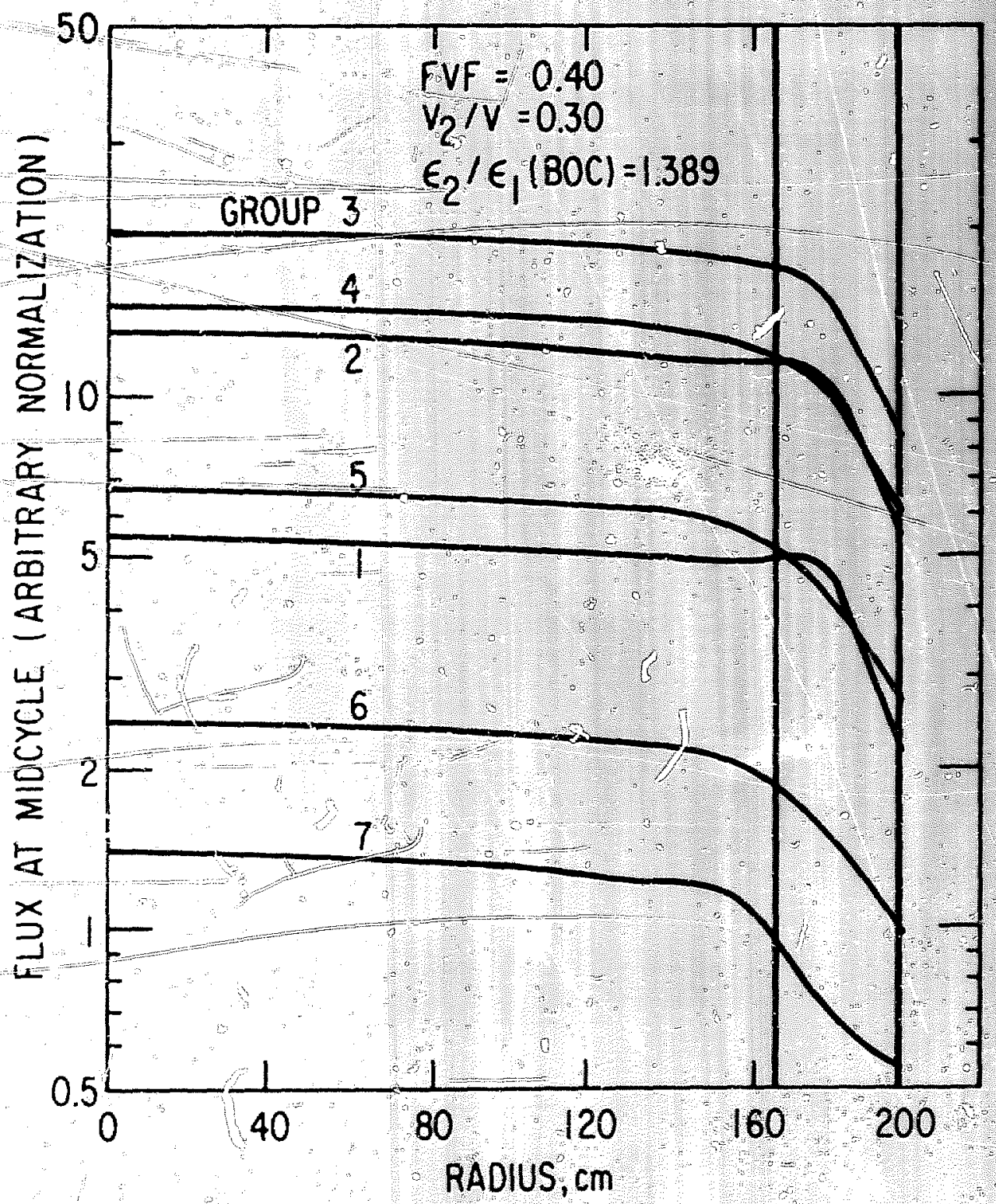

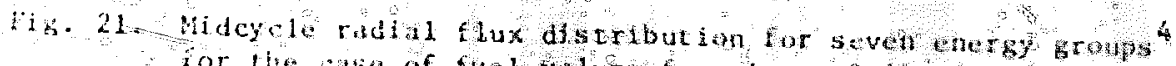
ior the catse of fuel volute fractim $=0.40$, volume splt $v_{2} / V=0.3$, and optimusurn-ycle beginning-ot-cycle enrichment splic $e_{2}$ i $(B Q C+1.389)$. 


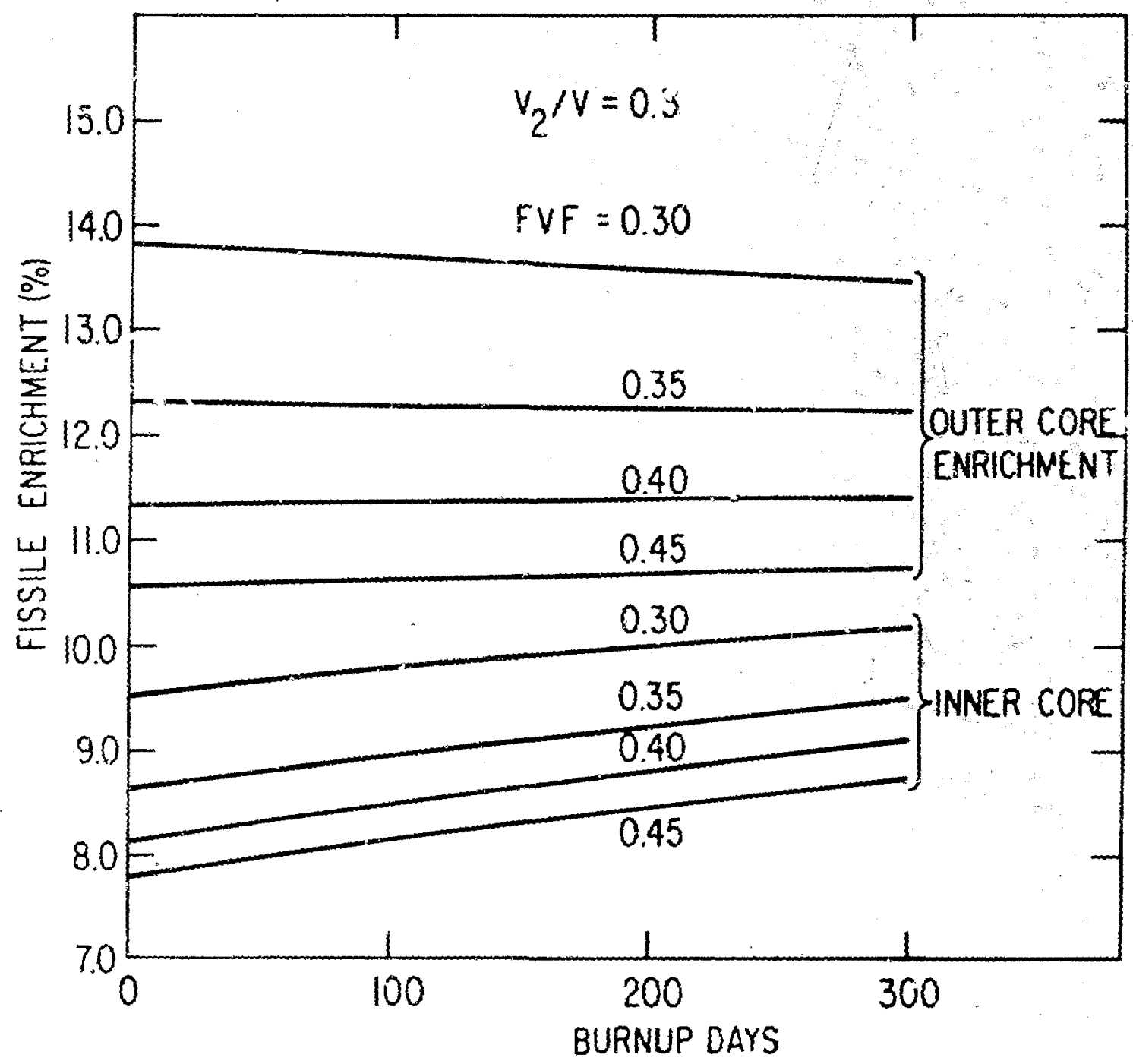

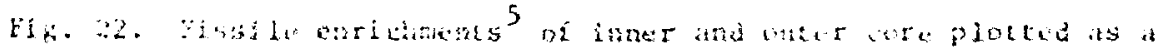

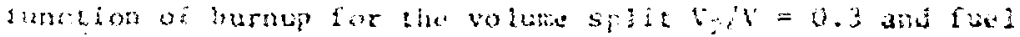

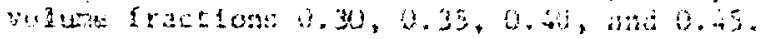

